\title{
Gênese, Impacto e Identidade da Revista de Administração Contemporânea
}

\author{
Genesis, Impact, and Identity of the Journal of Contemporary Administration
}

\author{
Luciano Rossoni ${ }^{1}{ }^{\oplus}$ \\ Rodrigo Assunção Rosa ${ }^{\circledR}$
}

\section{RESUMO}

Contexto: como as pessoas e as organizações, os periódicos também apresentam uma identidade. Assim, pensar na identidade de um periódico científico remete, em primeiro lugar, a compreender como sua trajetória moldou suas preferências acerca do que seus membros entendem sobre ciência e academia. Em segundo lugar, remete a como ele se projeta na comunidade científica, tanto em termos de regras de julgamento sobre o que é considerado válido como pesquisa quanto da intensidade e do modo como ele impacta o conhecimento científico e a realidade social. Objetivo: diante desse contexto, buscamos, neste artigo, recuperar elementos distintivos da Revista de Administração Contemporânea (RAC) em sua gênese, ressaltando como tal período deixou uma impressão duradoura em sua identidade. Método: utilizamos textos históricos e depoimentos para embasar nossos argumentos, triangulando o material qualitativo com padrões de citação, de referência e de escrita científica para evidenciar a identidade e o impacto da RAC. Resultados: as análises apontam que a RAC, desde sua gênese, diferenciou-se pelo rigor teórico, metodológico e empírico. Isso refletiu, ao longo do tempo, em seu impacto e centralidade na comunidade acadêmica. Conclusão: defendemos que a eficácia na construção da identidade da RAC a levou a ser o periódico mais influente da área de administração.

Palavras-chave: periódicos; impacto; identidade; impressão organizacional; comunidade científica.

Classificação JEL: B15, N16, M1.

\footnotetext{
${ }^{1}$ Universidade do Grande Rio, Programa de Pós-Graduação em Administração, Rio de Janeiro, RJ, Brasil.

${ }^{2}$ Universidade Positivo, Business School, Curitiba, PR, Brasil.
}

\section{ABSTRACT}

Context: just like people and organizations, journals also have an identity. Thus, thinking about the identity of a scientific journal leads, first of all, to an understanding of how its trajectory has shaped the journal's preferences about what its members understand regarding science and academia. Second, journals refer to how they project themselves in the scientific community, both in terms of rules for judging what is considered valid as research and of the intensity and ways of impacts that they have over scientific knowledge and social reality. Objective: given this context, we seek, in this article, to recover distinctive elements of the Journal of Contemporary Administration (RAC) in its genesis, highlighting how this period left a lasting imprint on its identity. Method: we use historical texts and testimonies to support our arguments, triangulating the qualitative material with citation, reference, and scientific writing standards to highlight the identity and impact of RAC. Results: the analyzes show that RAC, since its genesis, has been differentiated by theoretical, methodological, and empirical rigor. This reflected, over time, its impact and centrality in the academic community. Conclusion: we argue that the effectiveness in the construction of RAC's identity has led it to be the most influential journal in the administration area.

Keywords: journals; impact; identity; organizational imprinting; scientific community. 


\section{INTRODUÇÃO}

Periódicos científicos constituem uma das peças fundamentais da comunicação científica. É por meio dos periódicos que as diferentes comunidades acadêmicas se organizam na produção e disseminação do conhecimento científico (Vessuri, 1995); tornam-se meios legítimos de representação daquilo que seus membros consideram útil e válido enquanto ciência, refletindo a identidade social dos pesquisadores de determinado campo científico (Ashforth \& Mael, 1989; Bourdieu, 1975; Giampapa, 2011). Não obstante, um dos desafios centrais dos periódicos está na constituição de sua identidade frente à sua própria comunidade, na busca de sua distinção perante os demais (Faems, Filatotchev, Harley, \& Siegel, 2016).

Em face de tal desafio, buscamos reconstituir o surgimento da Revista de Administração Contemporânea (RAC) para compreender como sua identidade, enquanto periódico científico generalista de administração, desenvolveu-se ao longo dos anos. Para tanto, assumimos que sua gênese se deu no seio da própria comunidade científica (Guimarães, Motta, Farias, Kimura, Quintella, \& Carneiro, 2018), representada pela Associação Nacional de Pós-Graduação e Pesquisa em Administração (Anpad). Consequentemente, as exigências e pressões existentes no próprio contexto ambiental da formação da Anpad imprimiram na RAC seus elementos constitutivos.

Tratar da RAC enquanto periódico que carrega sua própria identidade e relevância em seu contexto de atuação é antes de tudo compreender sua gênese no berço da comunidade em que se formou. A consolidação de um periódico científico reside principalmente no desafio de estabelecer sua legitimidade na comunidade científica em que pretende lograr êxito. Aqui, portanto, a noção de comunidade é central no estabelecimento do nexo entre a criação da RAC e o seu desenvolvimento no contexto acadêmico de administração no Brasil. De acordo com Harrison e Stephen (1995), as comunidades se constituem enquanto sistemas simbólicos compartilhados que buscam representar diversificadas maneiras pelas quais os grupos sociais se organizam e se distinguem em nossa sociedade. Pertencer a uma comunidade implica que determinadas pessoas ou organizações serão membros e outras não, diferenciandose principalmente por meio das fronteiras estabelecidas pelas atividades simbólicas dos grupos, ou seja, por meio de modos específicos de conhecer, acreditar e persuadir (Harrison \& Stephen, 1995).
Nesse aspecto, um dos propósitos centrais dos periódicos científicos está na sua função enquanto canal de comunicação do discurso acadêmico das comunidades, isto é, de representar e refletir em seu processo discursivo e estrutura os padrões, critérios e pensamentos pertencentes ao campo social simbólico de pesquisadores que compartilham significados similares (Harrison \& Stephen, 1995). A RAC tem se diferenciado desde sua gênese, especialmente por refletir, por meio da idealização de seus próprios membros, os anseios e necessidades da comunidade científica de administração no preenchimento de lacunas deixadas por outros periódicos e canais de comunicação científicos. Ela se destaca também pelos seus impactos e pela percepção de utilidade pelos seus membros enquanto canal legítimo do processo discursivo de comunicação entre os pares, desenvolvendo, assim, uma identidade única que perdura até os dias de hoje.

A partir do conceito de impressão organizacional desenvolvido por Stinchcombe (1965) e da análise empírica de suas características essenciais, contribuímos para o entendimento de como as organizações se originam e persistem a partir de certas características herdadas de seu ambiente, aqui representadas pela compreensão da gênese, impacto e identidade da Revista de Administração Contemporânea (RAC). Ao investigarmos essas três dimensões centrais, desvelamos a trajetória única e peculiar de constituição da identidade de um periódico científico. Consequentemente, apontamos como a concepção identitária de um periódico, visto aqui como uma organização, manifesta-se em todas as suas ações editoriais, em que qualquer produto, processo ou resultado que se desdobre de sua ação, conscientemente ou não, mantém coerência com aquilo que é distintivo e essencial.

Para representar as contribuições centrais de nosso trabalho, dividimos o artigo em três principais partes. Na primeira, buscamos resgatar a criação da RAC a partir de sua gênese, que se deu no âmago do processo de institucionalização da Anpad; nesta parte, demonstramos que as características e o posicionamento do periódico frente aos demais refletiam fortemente as preocupações centrais da comunidade acerca do seu ambiente socialmente construído desde sua origem. Em segundo lugar, evidenciamos por meio da ideia de impacto acadêmico e social as principais marcas deixadas pela RAC frente à sua comunidade e entornos, ou seja, sua trajetória e contribuição enquanto periódico científico de relevância dentro e fora do contexto acadêmico brasileiro de administração. Por fim, refletimos sobre os desdobramentos desses vários desenvolvimentos na atual identidade do periódico, no intuito de 
compreender como a RAC buscou se distinguir dos demais periódicos da área de administração, destacando os atuais e futuros desafios não apenas na manutenção de sua legitimidade no contexto nacional, como também na procura pela inserção internacional de sua produção científica.

\section{A GENESE DA REVISTA DE ADMINISTRAÇÃO CONTEMPORÂNEA}

O tempo deixa marcas indeléveis. E, por mais que os tempos atuais remetam a desafios muito distintos dos do passado, é inegável que tais marcas nos relembram, a todo o momento, que o passado ainda está vivo. Isso vale tanto para as pessoas como para as organizações. Assim, se assumimos que os periódicos podem ser encarados como entidades coletivas, faz todo sentido vê-los como organizações que carregam, em sua identidade, características impressas desde a sua fundação. Por essa razão, como buscamos aqui falar da identidade da RAC, não teria como negar o contexto ambiental e histórico de seu nascimento, bem como os interesses e desejos daqueles que atuaram como empreendedores institucionais no momento do seu nascimento. E como demonstraremos aqui, as circunstâncias do período de fundação da RAC deixaram estampado aquilo que ainda é distintivo enquanto periódico acadêmico da área de administração.

Por essa razão, buscamos compreender a RAC a partir do contexto de sua gênese, já que é inegável que as organizações são marcadas pelas características ambientais do período de sua fundação (Marquis \& Tilcsik, 2013). Com efeito, sendo uma revista da área de administração, procuramos em teorias organizacionais os fundamentos conceituais sobre os efeitos do momento de criação da RAC na sua identidade. Isto requereu-nos o uso da organizational imprinting theory (Stinchcombe, 1965), literalmente traduzida como 'teoria da impressão organizacional', pois tal teoria explica as formas organizacionais a partir do momento de seu nascimento.

Cunhada no célebre texto de Stinchcombe (1965), Social structure and organizations, a ideia de impressão organizacional remete ao fato de que características herdadas do contexto de criação de uma organização persistem para além da fase de fundação (Marquis \& Tilcsik, 2013). Stinchcombe (1965), mesmo não definindo conceitualmente o que seria impressão organizacional, ressaltou que forças políticas e sociais que se manifestam no nascimento das organizações imprimem a sua marca. Consequentemente, o autor teorizou que há uma relação entre idade e estrutura das organizações, já que "organizações formadas em um momento normalmente têm uma estrutura social diferente das formadas em outro momento" (Stinchcombe, 1965, p. 163).

Diante da ausência de definição sobre impressão organizacional, mais recentemente, Marquis e Tilcsik (2013) a definiram "como um processo pelo qual, durante um breve período de suscetibilidade, uma entidade focal desenvolve características que refletem características proeminentes do ambiente, e essas características continuam a persistir, apesar das mudanças ambientais significativas nos períodos subsequentes" (Marquis \& Tilcsik, 2013, p. 199). Ainda, segundo os dois autores, essa definição remete a três características essenciais: (1) a existência de um período marcado por alta suscetibilidade à influência ambiental; (2) o intenso impacto do contexto ambiental durante esse período, a ponto de que a organização passe a refletir os elementos de tal contexto; (3) a durabilidade das características adquiridas no nascimento, apesar das mudanças ambientais subsequentes.

Como demonstraremos aqui, essas três características se manifestaram na trajetória da RAC. Por isso, enfatizamos os elementos de cada uma delas para melhor entender as impressões que o contexto de fundação deixou no periódico. Iniciando pela primeira característica, que é a existência de um período específico marcado por alta suscetibilidade, gostaríamos de retornar a um momento específico da história da Associação Nacional de Pós-Graduação e Pesquisa em Administração (Anpad), mais precisamente os anos de 1985 e 1986: a quinta presidência da Anpad, representada pelo professor Roberto Venosa.

Apesar de tal período ter ocorrido 10 anos depois dos ensaios da fundação da Anpad, em 1976, e 10 anos antes dos preparativos do lançamento da revista, foi na gestão de Venosa que começou a ser executado um projeto de Anpad enquanto organização, cujo projeto de associação está intimamente ligado ao projeto de criação da RAC, tempos depois. Como ressaltou Venosa, a Anpad era extremamente dependente dos programas de pós-graduação para a execução das suas atividades, seja dos encontros anuais, seja dos testes de seleção. Nas palavras de Venosa, "nada havia, tudo estava por construir" (Machadoda-Silva, 1997a, p. 155).

Por ainda não ter sido formalmente constituída, a Anpad apresentava alta maleabilidade. Como bem apontaram Immelmann (1975) e Marquis e Tilcsik (2013), esses breves períodos mais sensíveis abrem uma janela de 'imprintabilidade' para que as condições ambientais impactem em maior grau que em outros períodos nos quais tal janela já está fechada. Por essa razão, é fundamental capturar 
os sinais que tal momento apresentava para compreender como ele marcou a criação da Anpad, que, por sua vez, também marcou a fundação da RAC, pouco mais de 10 anos depois.

Já que a Anpad buscava se constituir, era necessário criar as condições para que isso ocorresse. Então, como dito por Venosa,

a força política [para criar a Anpad] deveria reunir mais que alguns poucos e de preferência vários muitos. Era preciso determinação, legitimidade, capacidade de articulação, representatividade regional, peso específico nos respectivos programas e propensão para agir em grupo. Em princípio, era um projeto para no mínimo seis anos. ... De substantivo buscava-se maior estabilidade com previsibilidade de recursos para os encontros anuais, uma carta de princípios ainda que não escrita, maior poder de barganha junto às demais áreas, maior capacidade de orquestração com os organismos oficiais tais como Capes, CNPq, Finep, Fapesp ... (Machado-da-Silva, 1997a, p. 155).

Em tal fala, percebe-se as condições sociais, bem como os recursos necessários, para a emergência de uma associação científica que combinasse, em sua forma organizacional, os meios pelos quais tais condições fossem atendidas com os processos técnicos de captação de recursos. Mas o que se ressalta é a necessidade de legitimar a área de administração por meio da associação, perante os programas dispersos regionalmente, as demais áreas e os organismos oficiais.

Naquele momento, falar em se legitimar significava dizer que a academia em administração deveria se tornar mais significativa tecnicamente e, especialmente, cientificamente. E muitas das ações para que isso ocorresse foram operacionalizadas nas duas gestões posteriores (Fachin, 2006): na gestão de 1987-1988, cujo presidente foi Clóvis L. Machado-da-Silva, que havia sido diretor científico na gestão anterior; e na gestão 1989-1990, sob a presidência de Suzana Braga Rodrigues, que também participou da gestão de Venosa como diretora administrativa.

Como fiel institucionalista que era, o professor Clóvis Machado-da-Silva tinha verdadeira obsessão pela legitimação da Anpad como associação científica. E não somente da Anpad, mas também da área. Por ser formado em sociologia, uma área cujo questionamento acerca de sua cientificidade já tinha sido superado, o fato de a administração não ser reconhecida pelas demais áreas o incomodava profundamente. Nada melhor que suas palavras para demonstrar tal incômodo:

$\mathrm{Na}$ época, diversas associações científicas estavam consolidadas e várias outras, criadas recentemente ou nem tanto, procuravam alargar o seu nível de aceitação institucional. A Administração, como área de conhecimento e ação, muitos diriam mais de ação que de conhecimento, encontrava dificuldades para lograr ampla legitimidade institucional em contexto no qual era visualizada como composta de profissionais aprisionados pelo mercado e, portanto, sem o necessário distanciamento, para não dizer capacidade analítica, para a produção substantiva de conhecimento científico. Quase sempre ignorada em função desse possível aprisionamento, à Anpad e aos representantes da comunidade acadêmica de Administração nas agências de fomento, cabia espaço reduzido em foros como CNPq, Capes, Finep e SBPC (Machado-da-Silva, 1997a, p. 155).

Para aqueles que o conheceram, sua concepção de ciência e de academia o acompanhou por toda a sua trajetória acadêmica. E como ele foi muito ativo em todo o processo de consolidação da Anpad, é inegável que tal concepção marcou profundamente o embrião da associação - não somente devido ao seu papel como empreendedor institucional, mas porque muitos dos que o seguiram nas demais gestões da Anpad compactuavam com tal visão.

Como ele próprio mencionou (Machado-daSilva, 1997a), o projeto de legitimação institucional da Anpad no contexto científico foi ampliado na gestão posterior, de Suzana Braga Rodrigues (19891990) - em boa parte, também porque ela teve papel central nos quatro anos anteriores, pois havia ocupado duas diretorias diferentes: administrativa (1985-1986) e científica (1987-1988). Nas palavras da professora, “... a Anpad, enquanto instituição política, procurava fortalecer a legitimidade de sua face acadêmica ..." (Machado-da-Silva, 1997a, p. 160). Ela inclusive compartilhava da preocupação de se recuperar o status da administração enquanto ciência, aproximando-a das demais ciências sociais, apesar de ter ressaltado que tal discussão, naquele momento, já era politicamente irrelevante.

Mas há mais elementos distintivos na gestão de Suzana Braga Rodrigues que são relevantes, que ascenderam naquela época e que são retomados até hoje. O primeiro é a luta entre programas de diferentes regiões do país por espaço e representatividade, pois sempre houve concentração de recursos e maior influência política por parte dos programas da Região Sudeste. O segundo é a relativa independência do 
modelo da pós-graduação em administração no país, distanciando-se de modelos estrangeiros, em especial do americano. E o terceiro e último era o aumento da influência das agências de fomento e de regulação nos programas da área, encorajando uma política de construção do conhecimento por meio da pesquisa científica.

Na gestão seguinte, cuja presidência foi exercida por Tânia Fisher (1991-1992), há uma preocupação com a legitimidade da área, mas o foco foi muito mais externo. Como apontou Fachin (2006), a representatividade da área foi colocada em voga, com a preocupação de evidenciar o papel da Anpad como sua representante perante as demais associações e agências de fomento. Já que o embate sobre as questões de legitimação interna estava parcialmente sanado, a Anpad punhase como ator político, reivindicando recursos nos órgãos oficiais (Fachin, 2006). Isso só foi possível porque a área já estava se consolidando, permitindo que emergisse uma identidade, pelo menos embrionária.

No biênio 1993-1994, Clóvis Machado-daSilva assume como o primeiro presidente eleito por uma segunda vez. E mesmo ele definindo que tal mandato "deu-se em circunstâncias diferentes", a preocupação com a legitimidade da área perdurava. Em suas palavras: "Apesar do olhar ainda desconfiado de várias outras áreas de conhecimento, em especial as consideradas mais nobres, não havia como negar que a Anpad já possuía certa presença no contexto científico e tecnológico brasileiro. Não a que pode e precisa ter, mas a que tinha sido possível construir até aquele momento" (Machado-da-Silva, 1997a, p. 164).

Para quem o conhecia, frases do tipo perduraram por mais de uma década, mesmo que isso pudesse deixar alguém descontente. No entanto, naquele momento em particular, algo era muito diferente da gestão anterior. Mesmo ainda existindo questionamentos sobre a legitimidade da área, o professor Clóvis retornava ao seu antigo posto como alguém que tinha ocupado, por dois mandatos (1989-1990 e 1991-1992), a presidência do Conselho Técnico Científico da Capes, instância máxima no sistema de avaliação da agência. Isso o elevava a um status no meio acadêmico nacional que ia muito além da área de administração. Status talvez maior, naquele momento, do que o da própria Anpad. Sendo uma pessoa muito persuasiva, e com uma autoridade que nenhum outro presidente teve até aquele momento, não foi difícil para ele solidificar as concepções de academia já delineadas no biênio 1985-1986, quando foi diretor científico. Além disso, o caminho para alçar novas empreitadas em nome da Anpad também estava aberto, entre elas, a constituição da Anpad como pessoa jurídica legalmente instituída e o "o lançamento de revista acadêmica, vinculada à Anpad, com perfil diferenciado das existentes" (Machado-da-Silva, 1997a, p. 167).

Essas novas empreitadas foram concretizadas na gestão posterior (1995-1996), sob a presidência de Peter Spink. No que se refere ao registro legal da Anpad, Spink destaca que os membros da assembleia aproveitaram “... a oportunidade para revisar ... os estatutos atuais. Boa parte das alterações se referia a práticas já estabelecidas, entretanto não registradas" (Machado-da-Silva, 1997a, p. 168). Para os que já passaram por um processo de constituição de um estatuto de uma associação, pode-se dizer que ele serve muito mais como um instrumento de consolidação de ideias e desejos do que um mecanismo de inauguração de uma nova fase. Por isso, entendemos que foi nesse momento que se fechou a janela de alta suscetibilidade à influência ambiental da Anpad.

Emtermos deimpressão organizacional, estava se encerrando o momento de 'imprintabilidade' da Anpad. Mas ainda dentro deste intervalo, algo de muito relevante foi incorporado nos eventos da Anpad: o processo de avaliação duplo-cego de artigos, o blind review (Fachin, 2006). Mais do que uma prática de revisão, o blind review é uma das mais importantes instituições da ciência, servindo inclusive de critério de demarcação do que é científico, numa visão falsificacionista. Por não ser comum na área de administração naquele momento, seu impacto era considerável. E foi na onda de tal impacto que foi realizado um teste-piloto de uma revista por parte da Anpad. Sob a edição geral do professor José Antônio Gomes de Pinho, os anais do EnANPAD de 1995, realizado em João Pessoa, foram publicados sob o nome de Revista Brasileira de Administração Contemporânea, cujo objetivo foi avaliar a viabilidade de uma publicação periódica (Fachin, 2006).

A aspiração para a criação de um periódico mostrou-se viável. Denominado Revista de Administração Contemporânea, o novo periódico da Anpad carecia de um editor. Não temos conhecimento de quais nomes eram elegíveis naquele momento. $O$ que sabemos, pelas palavras de Peter Spink, é que "foi com muita satisfação que todos receberam a notícia de que o professor Clóvis L. Machado-da-Silva estava inclinado a assumir o posto de editor" (Machado-da-Silva, 1997a, p. 170). Sendo coerente com toda a trajetória que relatamos aqui, não teria como ser outra pessoa. Então, em 1997, no mandato de Roberto Moreno, é publicada a primeira edição da RAC.

Fechou-se uma janela de 'imprintabilidade' na Anpad; no entanto, abriu-se outra janela na RAC, 
recém-criada. Logo, ela estava muito suscetível à influência ambiental. A diferença da janela da RAC é que vários dos elementos que constituíam seu ambiente emergiram durante o processo de amadurecimento da Anpad, sua mantenedora, não exatamente durante o período de gestação da revista em si - até porque a RAC era um projeto da Anpad e, mesmo tendo vida própria, era inegável que ela iria refletir as ideias e interesses da associação.

Naquele momento, as preocupações da associação acerca do seu ambiente socialmente construído, e agora da RAC, remetiam a seis pontos: (1) legitimar a área de administração como disciplina científica; (2) ser reconhecida pelas demais áreas de avaliação; (3) desvincular a área da imagem de mera reprodutora das experiências gerenciais, o que remetia a uma crítica ao gerencialismo; (4) ter maior profundidade teórica e maior rigor científico na pesquisa; (5) representar os programas de diferentes áreas e de diferentes regiões do país; (6) ter uma lógica de avaliação de artigos consolidada, como o blind review.

Com efeito, estando o contexto ambiental dado, é possível compreender a segunda característica do processo de 'imprinting' da RAC, que envolve o impacto considerável das preocupações sobre tal contexto em sua estrutura e processo (Marquis \& Tilcsik, 2013). E, pelo que ressaltamos aqui, muitas das preocupações acerca do ambiente institucional da Anpad poderiam ser parcialmente sanadas por meio da criação de um periódico acadêmico que atendesse a padrões reconhecidamente válidos de conduta científica. Afinal, não era possível ter uma associação científica que representasse uma disciplina sem ter um periódico que certificasse tal conhecimento (Vanderstraeten, 2010).

Se era essencial ter um periódico acadêmico para que a Anpad atendesse a seu desejo por legitimação, por que ele somente foi lançado 21 anos depois da criação da associação? Para responder a essa pergunta, gostaríamos novamente de resgatar Stinchcombe (1965). Segundo o autor, para que uma organização acenda como solução para um conjunto de problemas ambientais específicos, algumas condições devem ser atendidas. A primeira delas é a existência de uma elite que represente a entidade perante aqueles que controlam recursos essenciais, de forma que tais atores na sociedade se sintam representados em termos de estruturas, processos e propósitos organizacionais, garantindo que critérios básicos de aceitabilidade sejam atingidos (Stinchcombe, 1965). Ainda para o autor, esses recursos essenciais são poder, no senso de capacidade de coerção e persuasão, recursos financeiros próprios ou potencialmente disponíveis, e legitimidade moral. Segundo Stinchcombe (1965), "com esses recursos, é possível obter disciplina dentro da organização e o consentimento daqueles de fora, cujo consentimento é essencial" (Stinchcombe, 1965, p. 161).

Não somente o primeiro editor, na figura do professor Clóvis L. Machado-da-Silva, representava essa elite de que a RAC precisava para angariar os seus recursos materiais e simbólicos, mas também já havia sido instituído um corpo de pessoas que pudessem contribuir para que a empreitada fosse bem-sucedida. Esta seria uma segunda condição a ser atendida. Pois, apesar de a Anpad existir desde 1976, sua formalização somente ocorreu em 1995. Até esse momento, ficaria difícil imaginar como registrar formalmente um periódico, mais ainda como garantir os recursos necessários, como os que cobririam os altos custos de impressão, por exemplo.

Uma terceira condição seria garantir que existiria um aparato organizacional que fosse capaz de lidar com um periódico não vinculado a qualquer instituição de ensino, atendendo aos ideais de ciência e academia da Anpad. Sem contar que, para que tal aparato fosse justificável, uma quarta condição deveria ser atendida: que existisse um mercado fornecedor e consumidor para tal produto. Essas duas últimas condições foram muito bem atendidas pela trajetória de realização dos Encontros Nacionais da Anpad, que davam a dimensão, ao mesmo tempo, dos recursos materiais e do mercado fornecedor e consumidor de um periódico acadêmico nacional focado na pesquisa e não na aplicação gerencial. E naquele estágio, o EnANPAD já era um grande encontro, a ponto de que, nas palavras do ex-presidente da Anpad Roberto Moreno (biênio 1997-1998), o evento era "... frequentemente confundido com a própria associação, como se fosse a sua razão de ser ..." (Machado-da-Silva, 1997a, p. 171).

Sendo essas condições atendidas, o corpo diretivo da Anpad e especialmente seu editor-chefe ficaram incumbidos de selecionar aqueles aspectos historicamente específicos do contexto ambiental que, por sua vez, moldariam a RAC. E como bem ressaltaram Marquis e Tilcsik (2013), tal seleção reflete as tentativas de adequar-se às demandas ambientais por meio do isomorfismo, na intenção de reduzir as incertezas e conquistar legitimidade (DiMaggio \& Powell, 1983; Meyer \& Rowan, 1977). E pelo que nos parece, na sua primeira edição, a materialização da RAC refletiu em sua missão o desejo de adequação ao contexto ambiental: 
A RAC nasce com a missão de contribuir para o entendimento aprofundado da Administração mediante a divulgação de trabalhos de pesquisa e de análises teóricas que possam subsidiar as atividades acadêmicas e a ação administrativa. Ao abrigar contribuições analíticas, com base no pressuposto de que teoria e pesquisa empírica são interdependentes, pretende contribuir para a evolução do conhecimento, do diálogo e da inovação no campo da Administração (Machado-da-Silva, 1997b, p. 1).

Essa missão remetia a definir alguns parâmetros que deveriam ser atendidos para que a revista se diferenciasse das demais. Alguns deles foram definidos tacitamente. Por isso, buscamos ouvir o ex-presidente da Anpad e editor da RAC de 2002 a 2006, professor Tomas de Aquino Guimarães, para complementar e validar algumas informações ${ }^{1}$. Segundo o professor Tomas, desde o início, havia o entendimento de que era necessária uma revista da Anpad que fosse independente de qualquer instituição. Tal preocupação vinha do fato de que havia grande endogenia nos periódicos das instituições, cujo espaço para artigos de pesquisadores de outras escolas sem periódicos era reduzido. Isso inclusive ressaltava o conflito entre programas de regiões mais e menos favorecidas, pois os segundos se sentiam colocados de lado, pois não lhes era dado o mesmo espaço. Espaço negado não necessariamente pela ausência de mérito científico, mas por não pertencerem à escola editora do periódico.

Outro aspecto destacado pelo professor era o desejo de se instituir a prática do blind review na RAC, algo que não era comum nos outros periódicos. Isso vai ao encontro do primeiro editorial da revista: "o objetivo é praticamente só publicar artigos submetidos à apreciação da RAC; a tendência, nesse início, é a de aumentar gradualmente essa proporção à medida que ela se torne mais conhecida na comunidade acadêmica e nas organizações públicas e privadas" (Machado-da-Silva, 1997b, p. 1). Até porque, se a endogenia era grande, obviamente o processo não era blind review em muitos periódicos da época.

Outra preocupação destacada pelo professor Tomas, que é evidente em toda a trajetória da RAC e da Anpad, era a de ter um periódico que não reproduzisse uma lógica gerencialista. Esperava-se artigos científicos, analiticamente robustos, teoricamente consistentes e com alto rigor metodológico. Deveria ser um periódico acadêmico para ser consumido por pesquisadores, e não somente por gerentes. Isso poderia, até certo ponto, sacrificar a facilidade de leitura, reduzindo o público, porém ele seria mais seletivo e orientado para a pesquisa.

Por fim, Tomas também ressalta algo recorrente em toda a trajetória da Anpad: o desejo de se consolidar enquanto comunidade científica por meio de um periódico que representasse a produção qualificada, que passou pelo escrutínio da comunidade científica de administração. Isso era, inclusive, um desejo antigo do seu primeiro editor, Clóvis L. Machado-da-Silva, que sempre teve o ideal de que a administração fosse uma disciplina reconhecida pelas demais. Esse desejo sintetiza a visão dos fundadores da RAC: alcançar a legitimidade da revista perante uma ordem científica. E, para alcançar isso, ela precisava ser diferente.

Pelas evidências que nós buscamos do ano de fundação da RAC, comparando-as com a dos principais periódicos da área em 1997, ela efetivamente nasceu diferente. Na Figura 1, comparamos alguns padrões de referências, citações recebidas e endogenia da RAC com a Revista de Administração(Rausp), Organizações \& Sociedade (O\&S), Revista de Administração Pública (RAP) e Revista de Administração de Empresas (RAE). Para tanto, utilizamos dados do Spell, que concentra a maioria dos periódicos nacionais da área de administração, contabilidade e turismo, correspondendo a $42 \%$ da produção da área. Cabe ressaltar que a escolha dos quatro periódicos acadêmicos remete à relevância e capilaridade que eles tinham na época, pois os demais periódicos ou eram de outra área, ou não tinham projeção ou distribuição suficiente para atender a comunidade acadêmica nacional.

Primeiro, os dados apontam que os artigos publicados no ano de 1997 da RAC apresentaram, até hoje, maior média de citações (seis citações por artigo) do que todos os outros periódicos, o que ressalta a utilidade dos artigos da revista para um público qualificado de leitores, que é o de pesquisadores. Segundo, a média de referências por artigo da RAC naquele ano era maior do que todas as demais (28,6 referências por artigo), o que demonstra, pelo menos hipoteticamente, que os artigos buscavam maior fundamentação teóricoempírica. Terceiro, o número de referências a documentos estrangeiros era maior do que todos os outros periódicos (68\%), demonstrando o cuidado dos autores em fundamentar seus estudos com literatura internacional, algo que não era plenamente acessível na época como é atualmente. Quarto, o número de referências à produção qualificada e que passou pelo escrutínio de revisores era maior, pois $31 \%$ eram a artigos publicados em periódicos, demonstrando que a seleção de literatura era mais criteriosa. Por fim, a endogenia na RAC era muito inferior à dos demais periódicos, em que os $10 \%$ ali apontados se referem a artigos de dois ex-presidentes da Anpad. 


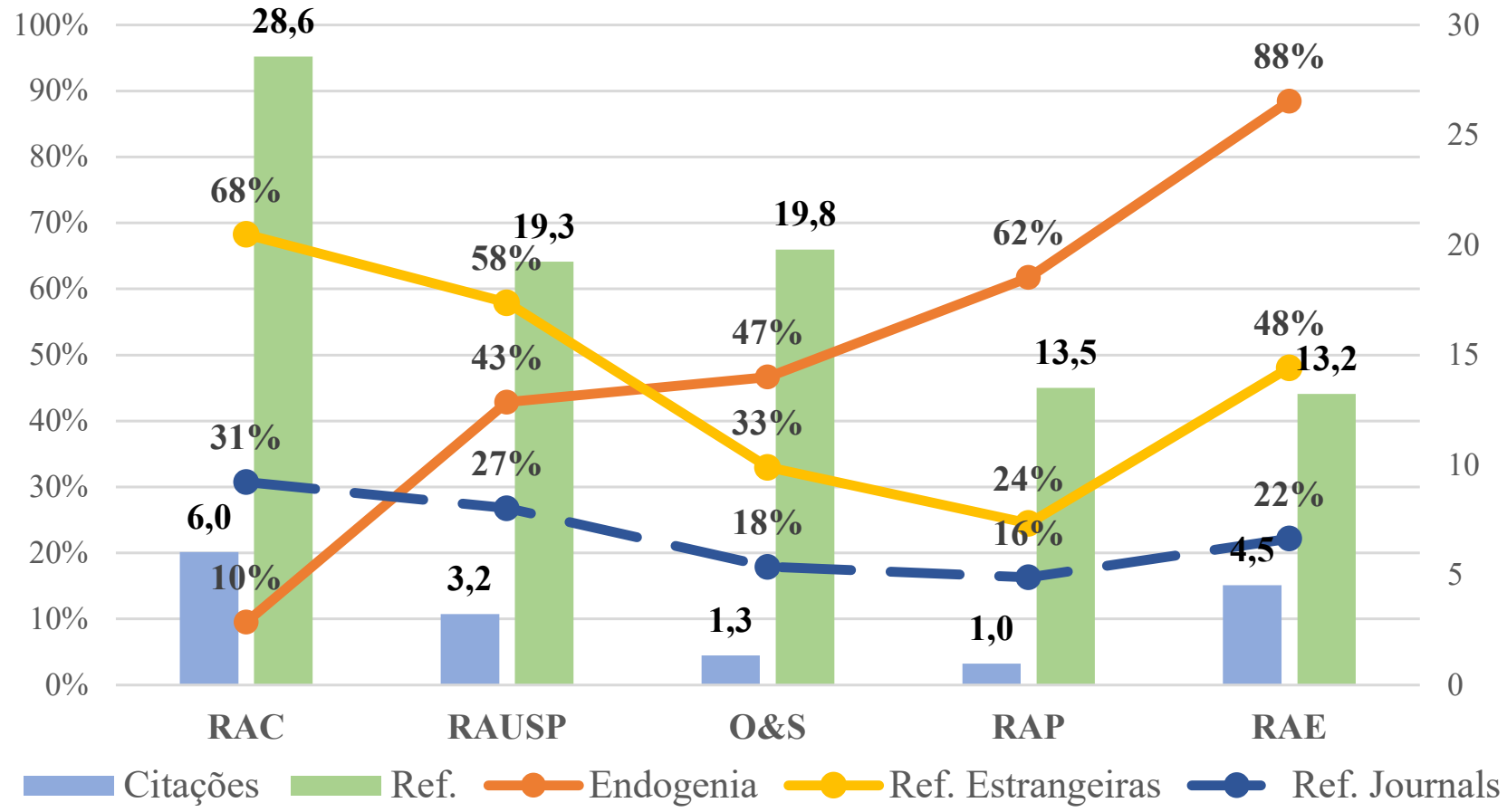

Figura 1. Referências, citações recebidas e endogenia no ano de fundação da RAC (1997).

Valores médios. Dados referentes aos 197 artigos publicados em 1997 nos cinco periódicos por autores nacionais. Citações recebidas no Spell até março de 2020. Considerou-se endogenia quando pelo menos um autor era da escola que edita o periódico. Para a RAC, considerou-se artigos de ex-presidentes. Artigos estrangeiros convidados (18 no total) foram desconsiderados no cálculo.

Legenda: Ref.: referências; Ref. Estrangeiras: referência a qualquer documento bibliográfico publicado no exterior; Ref. Journals: referência a qualquer artigo publicado em periódico, nacional ou internacional. Periódicos: Revista de Administração Contemporânea (RAC); Revista de Administração (Rausp); Organizações \& Sociedade (O\&S); Revista de Administração Pública (RAP); Revista de Administração de Empresas (RAE).

Esses resultados apontam que os desejos dos fundadores em responder às pressões por um periódico com teor mais acadêmico e científico estavam sendo atendidos, ressaltando que a RAC nasceu diferente. Há mais diferenças que merecem ser destacadas que não cabem num gráfico. Por exemplo, muitos textos de outras revistas possuíam um tom puramente gerencialista, sem qualquer preocupação com uma argumentação teórico-empírica, refletindo somente o interesse de aplicação de uma ferramenta gerencial. Quando havia citações, muitas delas remetiam a magazines, como Harvard Business Review, Business Week, entre outras. Sem contar que era prática comum citar documentos e livros não acadêmicos. Em suma, mesmo não podendo se descartar o esforço de alguns dos periódicos em ter uma publicação qualificada, em volume e consistência, não podíamos dizer que elas tinham um foco exclusivamente voltado para pesquisa, como era o caso da RAC.

Além de padrões de citação, referências e autoria, nós também capturamos aspectos ligados à lógica acadêmica por meio dos resumos dos artigos publicados pela RAC e pelos outros quatro periódicos no ano de 1997. Para tanto, nós apontamos a frequência de menções a um conjunto de termos que remetiam diretamente à lógica de pesquisa acadêmica, comparando-a entre as revistas. Os termos selecionados foram compostos pelas seguintes palavras: teoria, que incorporou palavras relacionadas como conceito, teórico e teoricamente; método; empírico ou empiricamente; análise e as palavras correlatas analisar e analítico; estudo; e pesquisa (pesquisar ou verificar).

Na Figura 2, nós ilustramos a frequência cruzada de cada um dos termos com cada um dos periódicos em um mapa de calor. Quanto mais intenso o tom verde, maior a proporção de artigos no periódico que faziam menção ao termo. O dendograma na parte superior da figura aponta para a similaridade e dissimilaridade entre os periódicos. O dendograma horizontal à esquerda aponta para a similaridade e dissimilaridade dos termos. 


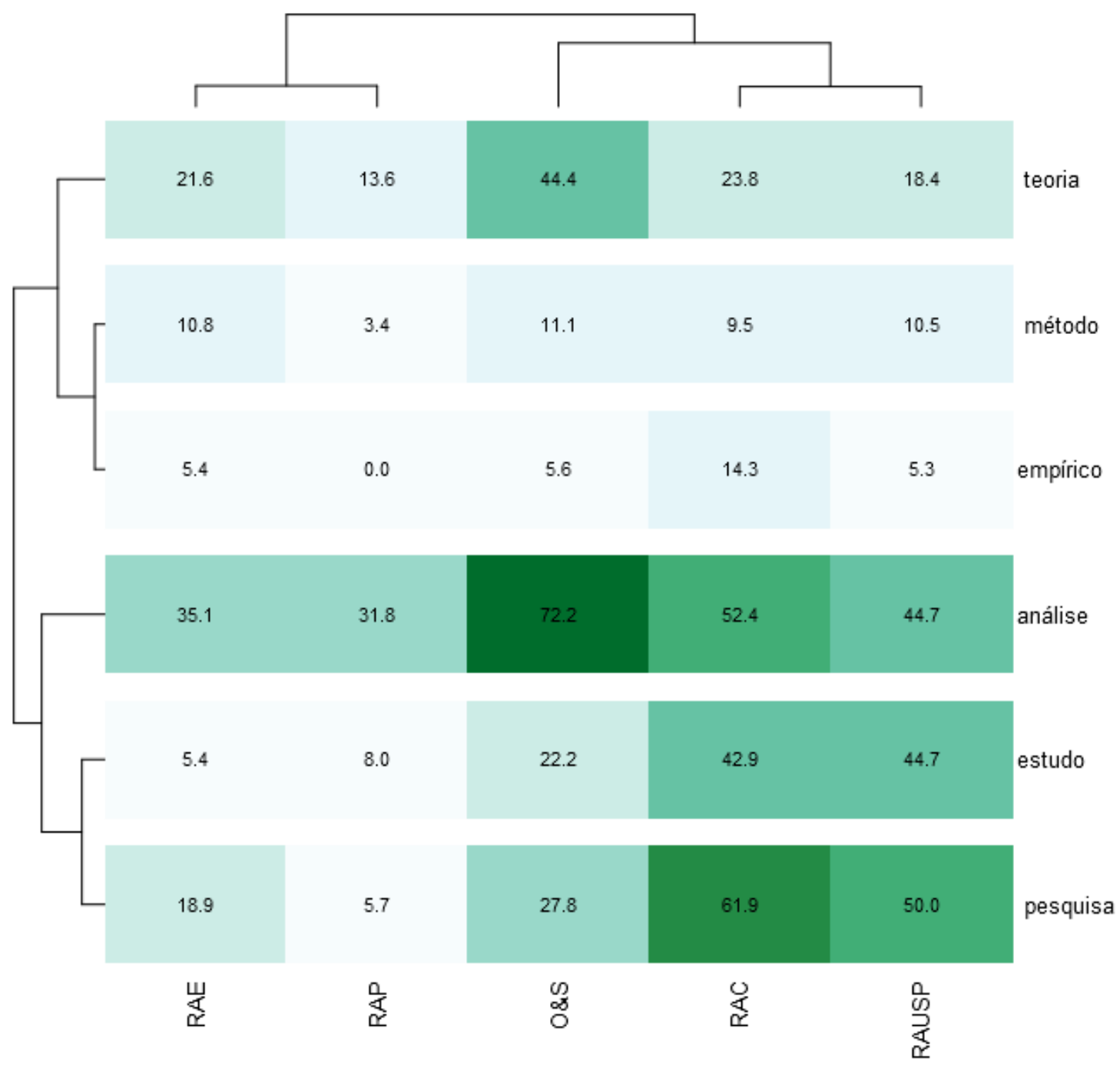

Figura 2. Coocorrência de termos que remetem à pesquisa (ano de 1997).

Termos capturados nos resumos de 202 artigos publicados em 1997 pelas cinco revistas. Células remetem à frequência de artigos que mencionaram cada termo. Termos que foram compostos por mais de uma palavra: teoria (conceito, teoria, teórico ou teoricamente); empírico (empírico ou empiricamente); análise (análise, analisar ou analítico); pesquisa (pesquisa, pesquisar ou verificar).

Legenda: Revista de Administração Contemporânea (RAC); Revista de Administração (Rausp); Organizações \& Sociedade (O\&S); Revista de Administração Pública (RAP); Revista de Administração de Empresas (RAE)..

Como pode ser observado na Figura 2, a frequência do termo pesquisa $(61,9 \%)$ é mais alta na RAC que nas demais, assim como a do termo empírico $(14,3 \%)$. Isso aponta para uma inclinação aparentemente maior da RAC para a investigação científica em relação às demais revistas. Quando olhamos para a frequência de outros dois termos na RAC, estudo $(42,9 \%)$ e análise $(52,4 \%)$, a frequência é bem alta, apesar de ser menor que a da O\&S no primeiro termo e um pouco menor que a da Rausp no segundo. Tais menções remetem a uma maior preocupação analítica desses periódicos em relação aos demais. No que se refere ao termo teoria, a RAC apresenta também a segunda maior frequência
(23,8\%), abaixo da O\&S. No nosso entendimento, o percentual destaca o quanto a teoria poderia ter um papel central nos argumentos dos artigos. Na menção do último termo, método, a frequência foi mais baixa do que três periódicos $(9,5 \%)$, apesar de a diferença não ser significativa.

Sintetizando tal análise, o que podemos deduzir de tal mapa de calor é que a RAC ascendeu como periódico que buscava conciliar teoria e pesquisa empírica em maior grau que os demais, o que reflete a sua missão declarada naquele mesmo ano pelo editor-chefe. Mesmo sendo próxima à Rausp acerca 
dos termos análise, estudo e pesquisa, ela se diferencia dessa revista nos termos empírico e teoria. Logo, a Rausp aparentemente se caracterizava como periódico focado primordialmente em pesquisa, não em teoria. Há também uma proximidade da RAC com a O\&S nos termos análise e teoria, mas não com os demais, cuja frequência era baixa. Nitidamente a O\&S se caracterizava, naquele momento, como um periódico de análise teórica, mas não empírica.

Enfim, os elementos que destacamos até agora evidenciaram como os aspectos do contexto ambiental de referência da Anpad no momento de fundação da RAC imprimiram elementos distintivos que a fizeram ser um periódico diferenciado dos demais desde a sua gênese. $\mathrm{O}$ que buscaremos destacar no restante deste artigo remete à terceira característica do imprinting: que, apesar de todas as mudanças ambientais subsequentes, os traços adquiridos na fundação ainda persistem (Marquis \& Tilcsik, 2013). Apontaremos tais traços na análise da trajetória de impacto científico e social da RAC e na concepção de identidade do periódico.

\section{PENSANDO NO IMPACTO DE UM PERIÓDICO CIENTÍFICO EM UMA ACADEMIA EM FORMAÇÃO}

A questão fundamental no processo de impressão organizacional não é necessariamente compreender como os aspectos ambientais inculcam a essência das organizações, mas especialmente como aquilo que foi inculcado persiste. Por um lado, há o entendimento de que as organizações são sistemas adaptativos, o que levaria as características do momento de fundação a se dissiparem. Por outro lado, como ressaltam Marquis e Tilcsik (2013), a inércia e a institucionalização fazem com que as organizações exibam traços duradouros do contexto de fundação.

Assim, apesar de todas as mudanças efetivas que o tempo ocasiona nas organizações, Stinchcombe (1965) sugere algumas razões para a persistência dos traços do nascimento das organizações. Primeiro, eles podem ser a forma mais eficaz de a organização atingir um objetivo, algo que tentaremos ressaltar em nossos argumentos sobre a trajetória bem-sucedida de ascensão da RAC. Segundo, forças tradicionalistas, a defesa de interesses e a constituição de ideais podem levar à preservação de estruturas. Isso é algo muito significativo de se dizer, até porque várias vezes a Anpad foi apontada como 'tradicionalista', cujas ideias e interesses de sua elite eram reforçados em vários ritos e cerimônias, muitos deles sendo reproduzidos na RAC. Terceiro, a organização pode não ter competição de outras formas alternativas que ameacem a sua sobrevivência, o que é relativamente nítido quando se trata da Anpad, já que a sua importância para a área ainda não foi colocada em cheque, bem como para a RAC, cujo modus operandi, até o momento, atendeu muito bem às expectativas da comunidade acadêmica local.

Diante de tais razões, o que queremos enfatizar é que, para que o modelo da RAC enquanto periódico perdurasse, alguma medida de sucesso deveria ser preenchida. E tal medida, no contexto atual da pesquisa, remete às formas de avaliar o seu impacto enquanto periódico científico.

\section{Definindo impacto}

O debate sobre os impactos da ciência tem levantado uma ampla discussão em diferentes campos do conhecimento sobre suas definições e formas de operacionalização e avaliação (Adler \& Harzing, 2009; Aguinis, Shapiro, Antonacopoulou, \& Cummings, 2014; Ashford, 2013; Butler et al., 2017; Lazzarini, 2017; Smith, 2012). Embora não exista uma definição única ou um claro consenso sobre o seu conceito, no geral, os pesquisadores têm definido o impacto como as influências e os benefícios resultantes do exercício da atividade de pesquisa científica para a academia e sociedade (Adler \& Harzing, 2009; Lima \& Wood, 2014). Portanto, analisar os impactos da atividade científica é aprofundar o entendimento sobre como os conhecimentos e resultados produzidos pelos diversos atores da ciência são criados e disseminados para diferentes públicos, sejam eles acadêmicos, profissionais ou a sociedade em geral.

Um dos principais desafios na discussão deste tema está na delimitação de como esses impactos podem ser mensurados a fim de que se consiga representar adequadamente as várias influências e resultados do conhecimento produzido (Birkinshaw, Lecuona, \& Barwise, 2016; Moed \& Halevi, 2015). Tal desafio se dá principalmente devido ao fato de que as dimensões e níveis de análise podem variar consideravelmente a depender do campo social de produção, tendo em vista que dependem do contexto em que são desenvolvidos e promovidos (Lima \& Wood, 2014; Moed \& Halevi, 2015). Nesse sentido, o campo científico onde a pesquisa é produzida é um fator relevante para tais delimitações. Por exemplo, os impactos gerados por físicos, biólogos, administradores e economistas certamente são diferentes e devem ser dimensionados de acordo com as possibilidades e limites de produção e disseminação do conhecimento de cada campo específico. Além disso, o nível de análise é também importante como recorte, dado que a depender do ator envolvido na produção do conhecimento - pesquisador, grupo de pesquisa, periódico, universidade, entre outros - irá também possuir distintas dimensões e níveis de impacto.

Sendo assim, ao evidenciarmos os impactos da RAC, estaremos em primeiro lugar tratando das influências e resultados que estão circunscritos ao campo científico mais específico de administração de empresas (Mingers \& Harzing, 2007; Rosa \& Romani- 
Dias, 2019; Rossoni, 2018b). Em segundo lugar, pretendemos também realizar essa discussão no âmbito das possibilidades de impacto dos periódicos científicos, haja vista que os indicadores e dimensões podem ser distintos de outros atores científicos, tais como pesquisadores, grupos de pesquisa e universidades.

A discussão sobre as formas de mensuração e indicadores de impacto de periódicos científicos na literatura é extensa, sendo que, na área de administração, pesquisadores também têm recorrentemente se debruçado em investigar os variados tipos de impactos, no contexto nacional ou internacional de pesquisa (Adler \& Harzing, 2009; Diniz, 2017; Ferreira, 2015; Harzing \& Van Der Wal, 2009; Rosa \& Romani-Dias, 2019; Rossoni, 2018b).

Em se tratando de periódicos científicos no contexto do campo da administração, embora também não haja ainda uma delimitação evidente entre os tipos de impacto existentes, podemos classificar os impactos de periódicos em dois principais tipos: impacto acadêmico e impacto social. A diferença central entre o impacto acadêmico e o social pode estar nas formas de mensuração e no dimensionamento das fronteiras que este impacto atinge (Lima \& Wood, 2014; Moed \& Halevi, 2015). Enquanto no impacto acadêmico a produção de conhecimento irá influenciar e beneficiar o próprio campo social em que a pesquisa é desenvolvida - ou seja, a esfera da ciência, da academia e de outros meios de produção do conhecimento -, o impacto social se distingue na medida em que esse impacto ultrapassa as fronteiras do próprio campo, sendo disseminado para outros públicos, tais como empresas, profissionais, mídia, políticas públicas e sociedade. Portanto, ao tratarmos de impacto acadêmico, lidamos com formas de como o conhecimento produzido pelos periódicos é utilizado e disseminado pelos próprios periódicos e pesquisadores. Já ao se investigar o impacto social, estaremos compreendendo como estes conhecimentos disseminados pelos periódicos são transferidos e como impactam as práticas empresariais e de ensino e a sociedade, a partir de novos entendimentos, modelos, técnicas, produtos e debates públicos ou da mídia (Butler et al., 2017; Lima \& Wood, 2014; Moed \& Halevi, 2015; Sugimoto, Work, Larivière, \& Haustein, 2017).

\section{Impacto acadêmico}

No que se refere ao impacto acadêmico, uma das principais medidas utilizadas para mensurar o impacto de periódicos tem sido a citação (Aguinis, SuárezGonzález, Lannelongue, \& Joo, 2012; Smith, 2012). Uma das premissas centrais da citação é a de que quando os pesquisadores citam outras pesquisas em seus artigos, estas são consideradas úteis e relevantes para o debate acadêmico, portanto, de algum modo, acabam influenciando a construção e disseminação do conhecimento científico (Simsek, Heavey \& Jansen, 2013). Nesse sentido, com base no mapeamento das citações dadas e recebidas pelos periódicos, diversas bases científicas e pesquisadores têm se debruçado em desenvolver uma série de indicadores de impacto com base nas relações de citação entre periódicos científicos (Rosa \& Romani-Dias, 2019).

Uma das métricas mais legítimas utilizadas no meio acadêmico é o chamado fator de impacto, também conhecido como Journal Citation Reports (JCR). Desenvolvido por Eugene Garfield (Garfield, 1955), sua primeira versão foi lançada em 1963 com o nome de Science Citation Index (Garfield \& Sher, 1963) por meio do Institute for Scientific Information (ISI). O ISI foi adquirido pela Thomson Reuters em 1975, que, por sua vez, foi incorporada pela Clarivate Analytics em 2016. Devido ao fato de que apenas a contagem de citações não representava adequadamente o impacto de periódicos, dado que alguns publicavam uma quantidade muito maior de artigos do que outros, foi realizada uma ponderação com base na quantidade de artigos publicados. Portanto, o fator de impacto passou a ser calculado pelo número de citações que o periódico recebeu nos últimos dois anos dividido pela quantidade de publicações do periódico, possibilitando que periódicos que publicam uma menor quantidade de artigos, mas que possuem uma relevante quantidade de citações, fossem considerados nos rankings de impacto científico (Garfield, 2006).

Com isso, diversas outras bases científicas também passaram a realizar cálculos similares, tais como o CiteScore, desenvolvido pelo Scopus e de propriedade da Elsevier, e os fatores de impacto de dois e cinco anos da base Scientific Periodicals Electronic Library (Spell), criados pela Anpad em 2012 para analisar os periódicos brasileiros de administração, contabilidade e turismo. Não obstante, outras métricas, tais como o Índice h, SJR e Eigenfactor, passaram a ser também empregadas, e assim como o JCR, são amplamente utilizadas como indicadores para mensurar o impacto, qualidade e relevância de periódicos tanto brasileiros como internacionais (Rosa \& Romani-Dias, 2019).

Embora as métricas de impacto acadêmico mencionadas sejam extensamente utilizadas em rankings de bases científicas, associações e órgãos governamentais ou de fomento à pesquisa, na literatura há um extenso debate sobre suas limitações, como também uma variedade de pesquisas que buscam contribuir com novas métricas e dimensões para além das abordagens baseadas em citações de periódicos (Hicks, Wouters, Waltman, De Rijcke, \& Rafols, 2015; Kaur, Radicchi \& Menczer, 2013). As proposições vão desde novas medidas baseadas em análise de redes (Hoffmann, Christoph, \& Miriam, 2014), como usaremos neste texto, métodos bibliométricos e cientométricos (Butler et al., 2017), até investigações 
que buscam analisar a multidimensionalidade do impacto acadêmico (Moed \& Halevi, 2015) ou que estejam fundamentadas em teorias como a de difusão da inovação (Simsek et al., 2013).

\section{A trajetória de impacto científico da RAC}

Apesar de a RAC não ter nascido efetivamente do zero, pois é inegável que seu prestígio estava associado ao status da Anpad, ela entrava no sistema de comunicação científica da área de administração com décadas de defasagem se comparada às revistas mais tradicionais, como a RAE, RAP e Rausp. A própria O\&S já tinha quatro anos de existência quando a RAC foi lançada. Isso dificultava a capilaridade do periódico, até porque a divulgação de artigos por meios eletrônicos não era o modelo padrão. Afinal, a internet brasileira era um empreendimento ainda nascente. Além disso, qualquer medida de impacto científico, inclusive por meio das citações, levava algum tempo. As mais simples, como o impacto de dois anos, só poderiam ser levantadas manualmente, dois anos depois da publicação.

Tanto que o primeiro levantamento realizado sobre o impacto dos periódicos da área de administração por Tinoco (2006) ignorou a RAC porque, segundo a autora, os artigos publicados entre 1997 e 2002 na revista não tinham sido significativamente citados. Naquele momento, Tinoco (2006) verificou que, entre RAE, RAP, Rausp e EnANPAD, a primeira foi a com maior impacto médio entre 1999 e $2002(0,357)$, seguida da RAP com 0,269 e o EnANPAD, um evento, com 0,232. Isso demonstra que, naquele momento, apesar das limitações na base de referências do estudo, que se limitou a quatro periódicos e um evento, a RAE era o periódico de administração com maior impacto.

Dois anos depois, Machado-da-Silva, Guarido Filho, Rossoni e Graeff (2008) fizeram uma análise do impacto dos anais do EnANPAD e dos periódicos classificados no Qualis como A ou B Nacional na área de administração no triênio 2005-2007. Tendo como base 22 periódicos e um evento, somente três anos após o último ano analisado por Tinoco (2006), a RAC despontou como o segundo periódico com maior fator de impacto, com uma média de 0,557 no triênio. Naquele triênio, a RAE ainda era o periódico com maior impacto por citações no país: média de 0,969.

Ao comparar o desempenho da RAC nos dois estudos, fica evidente a sua ascensão em um curto período, que remete aos seus 10 primeiros anos. Apesar de tais estudos apontarem para uma trajetória de ascensão, não havia qualquer recurso naquela época no Brasil para capturar o impacto dos periódicos nacionais da área. Isso começa a mudar em 2010 com a criação do Spell, que, mesmo tendo seu primeiro indicador de impacto gerado em 2014, tem dados de impacto e citações que remontam ao ano de 2010, e cujo dado mais recente é o impacto de 2018. Em posse de tais dados, na Figura 3, podemos ver a trajetória de impacto da RAC desde 2010.

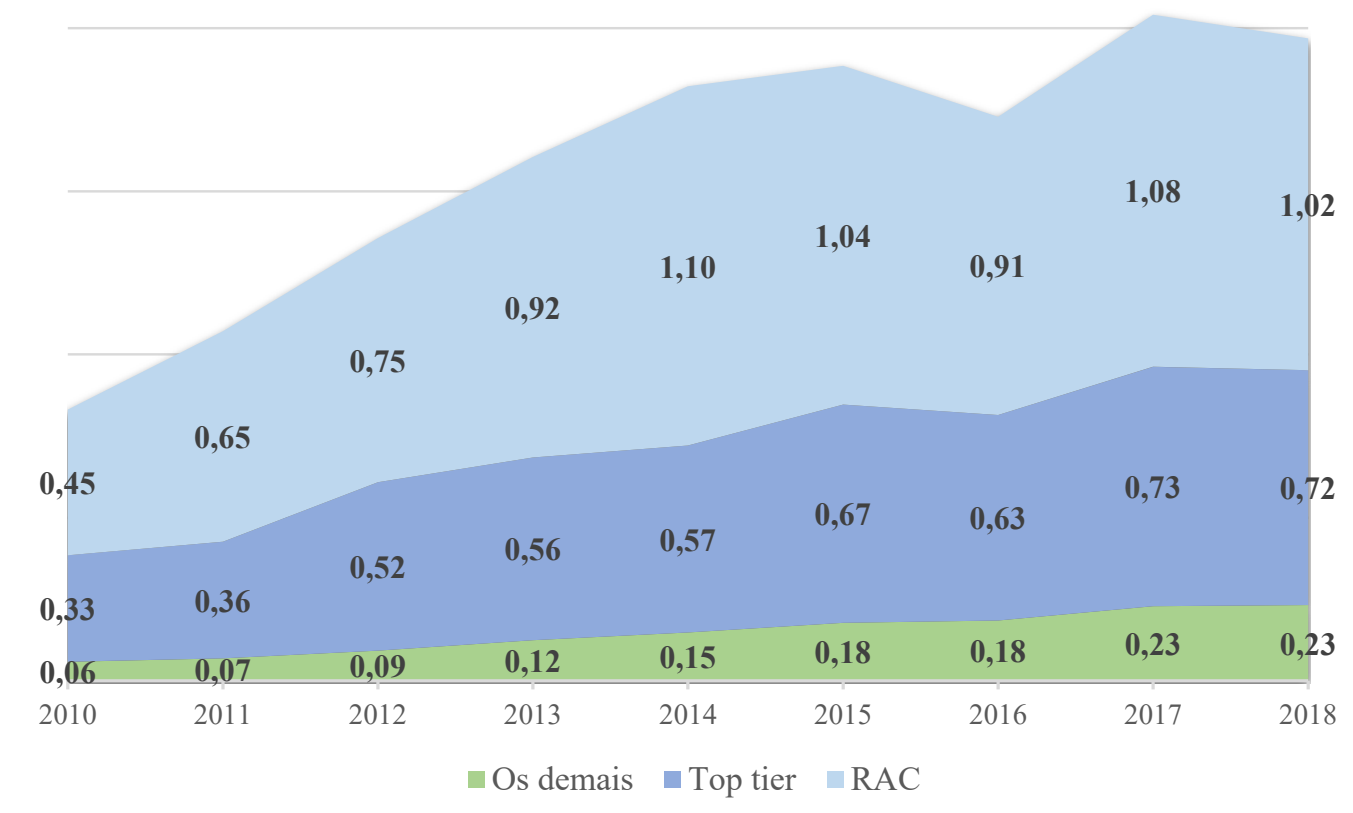

Figura 3. Trajetória de impacto de cinco anos dos periódicos do Spell de 2010 a 2018.

Dados do Spell, considerando-se o impacto de cinco anos sem autocitações: www.spell.org.br/impacto (recuperado em 20 de fevereiro de 2020 ). Periódicos top tier, dispostos por ordem de impacto: $1^{\circ}$ Revista Contabilidade \& Financas; $3^{\circ}$ Revista de Administracão de Empresas; $4^{\circ}$ RAE-eletrônica; $5^{\circ}$ Revista de Administração; $6^{\circ}$ Revista de Administração Mackenzie; $7^{\circ}$ Revista Contemporânea de Contabilidade; $8^{\circ}$ Revista de Contabilidade e Organizações; $9^{\circ}$ Revista de Administração Pública; $10^{\circ}$ Organizações \& Sociedade; $11^{\circ}$ Cadernos EBAPE.BR. Todos os demais: 110 de um total de 121 periódicos nacionais com impacto no Spell. 
Comparando o impacto de cinco anos da RAC no período com o impacto dos outros 10 periódicos mais centrais (top tier) e com o impacto de todos os demais periódicos que compõem o Spell, mesmo havendo um crescimento significativo no indicador para todas as revistas, é inegável que a RAC ascende como periódico de grande impacto na área. A ponto de que, entre 2010 e 2015, a RAC começou a revezar com a RAE como periódico de maior impacto da área de administração. Então, desde 2016, a RAC é o periódico nacional da área de administração, exclusivamente, com maior impacto, seja para uma janela de dois anos, seja para uma janela de cinco anos, com ou sem autocitações. Curioso destacar que foi quase 20 anos depois de seu lançamento que a RAC emergiu em tal posição, alcançando o status que seus fundadores almejaram, não em termos de estruturas e processos, somente, mas também de impacto. Afinal, os números importam (Mau, 2020).

Todavia, quando falamos de impacto científico, não podemos reduzir tal avaliação ao impacto pela média de citações. Como apontamos anteriormente, há outras medidas de impacto; algumas delas buscam capturar a centralidade e prestígio de um periódico por meio de redes de citações (Hoffmann et al., 2014). Por essa razão, para se ter alguma evidência empírica além do fator de impacto, analisamos a estrutura de citações dos periódicos pertencentes à base do Spell no ano de 2018. A Figura 4 representa graficamente a rede de citações.

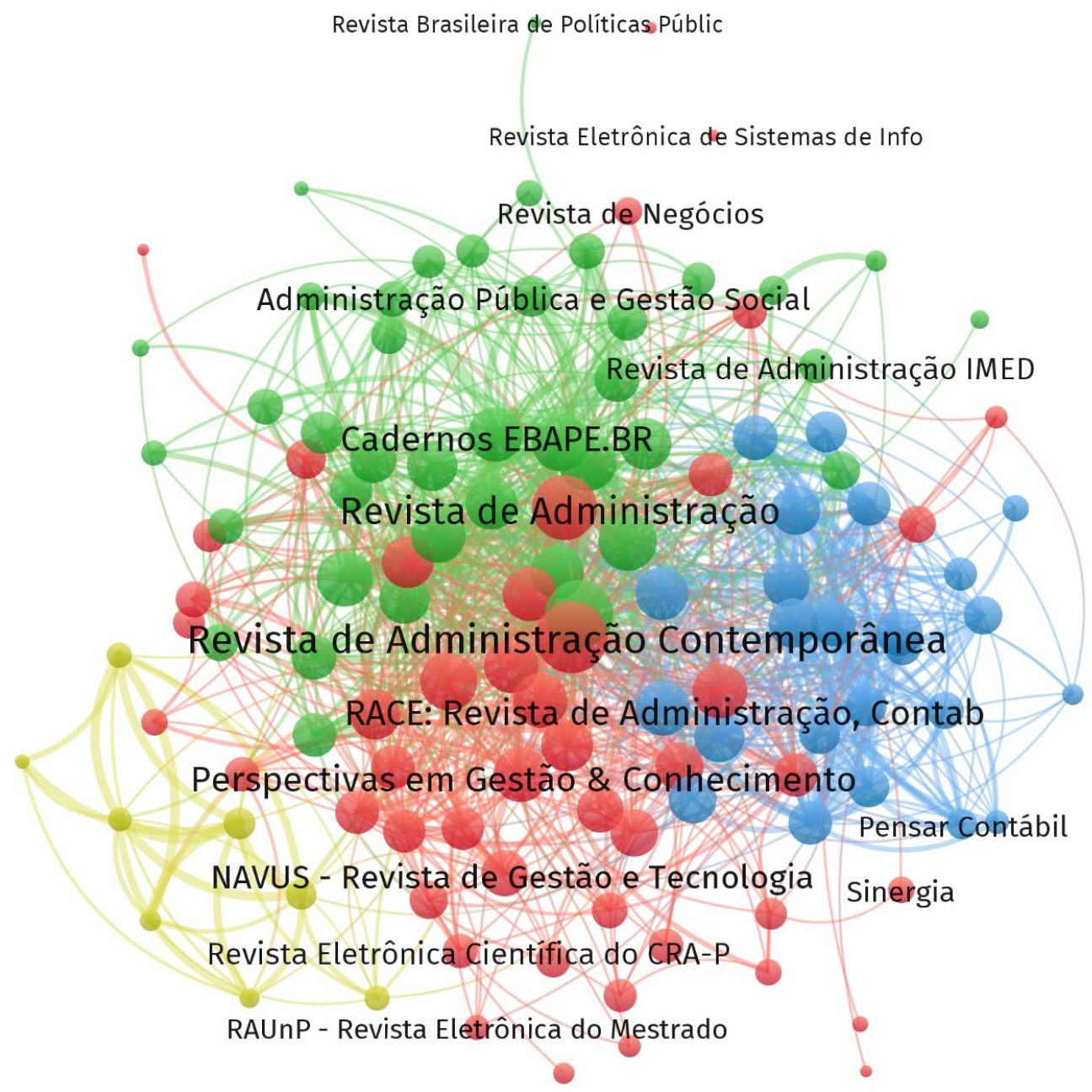

Figura 4. Rede de citações entre periódicos no Spell (ano de 2018).

Dados coletados nos artigos publicados no Spell no ano de 2018 (www.spell.org.br; recuperado em 20 de fevereiro de 2020). Considerou-se somente as citações recebidas de artigos publicados entre 2013 e 2017, que remetem aos últimos cinco anos. Periódicos citados: 120. Periódicos citantes: 118. Método de visualização do grafo: Kamada Kawai. A maioria dos rótulos foi omitida para facilitar a visualização. As cores apontam para clusters formados pela maior redundância de citações. Os clusters de cor vermelha e verde são os mais centrais, formados majoritariamente por periódicos da área de administração. O cluster de cor azul é formado predominantemente por periódicos da área de contabilidade. Já o de cor amarela tem grande presença de periódicos da área de turismo. 
Na Figura 4, fica evidente que a RAC é o periódico mais central, pois se posiciona exatamente no centro da rede, cuja posição é gerada pelo próprio algoritmo de visualização, que centraliza nós mais centrais e afasta nós mais isolados. Para complementar tal interpretação, listamos na Tabela 1 alguns indicadores de citação e de centralidade de redes dos 10 periódicos mais centrais. Como visto na
Tabela, a RAC é o periódico com maior centralidade na rede, com maior número de periódicos citantes (73,9\%) e com maior número de citações (248). Em termos de impacto sem autocitações, para dois ou cinco anos, o impacto da RAC é menor somente do que o da Revista Contabilidade \& Finanças, que é um periódico da área de contabilidade.

Tabela 1. Centralidade da RAC nas áreas de administração, contabilidade e turismo em 2018.

\begin{tabular}{|c|c|c|c|c|c|c|}
\hline \multirow{2}{*}{ Periódicos } & \multirow{2}{*}{$\begin{array}{l}\text { Centralidade } \\
\text { Ponderada }^{1}\end{array}$} & \multirow{2}{*}{\multicolumn{2}{|c|}{ Periódicos Citantes ${ }^{2}$}} & \multirow{2}{*}{ Citações } & \multicolumn{2}{|c|}{ Impacto $^{3}$} \\
\hline & & & & & 5 anos & 2 anos \\
\hline Revista de Administração Contemporânea & 144,4 & 88 & $73,9 \%$ & 248 & 1,017 & 0,663 \\
\hline Revista de Administração Mackenzie & 121,5 & 79 & $66,4 \%$ & 204 & 0,776 & 0,298 \\
\hline Revista de Administração Pública & 111,1 & 64 & $53,8 \%$ & 220 & 0,648 & 0,535 \\
\hline Revista de Administração de Empresas & 108,7 & 66 & $55,5 \%$ & 194 & 0,754 & 0,611 \\
\hline Revista de Administração & 101,8 & 70 & $58,8 \%$ & 153 & 0,685 & 0,400 \\
\hline Cadernos EBAPE.BR & 88,3 & 53 & $44,5 \%$ & 173 & 0,603 & 0,523 \\
\hline Revista Contabilidade \& Finanças - USP & 80,8 & 47 & $39,5 \%$ & 147 & 1,158 & 0,843 \\
\hline Revista Brasileira de Marketing & 80,2 & 56 & $47,1 \%$ & 154 & 0,518 & 0,292 \\
\hline Organizações \& Sociedade & 75,3 & 52 & $43,7 \%$ & 122 & 0,669 & 0,508 \\
\hline Brazilian Business Review & 65,7 & 48 & $40,3 \%$ & 93 & 0,500 & 0,333 \\
\hline
\end{tabular}

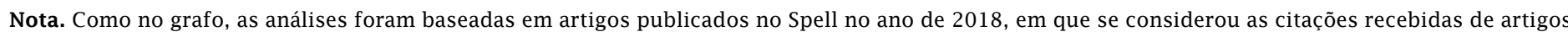

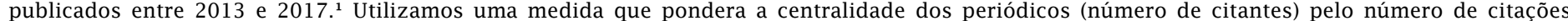

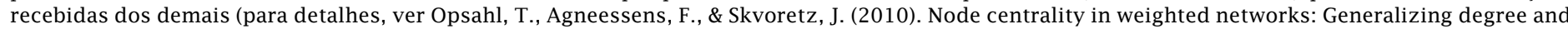

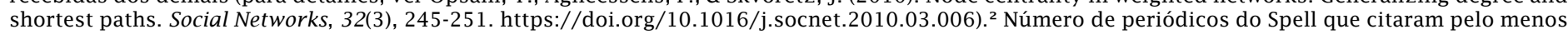
uma vez artigos de 2013-2017 do periódico citado em 2018. ${ }^{3}$ Impacto sem autocitações.

Mas além do impacto, o que diz tal centralidade na rede de citações da RAC? Ela aponta que, além de ser o periódico mais citado, a RAC é referenciada pela maioria dos periódicos da área, o que remete para sua utilidade em termos de referência teórico-empírica para uma gama maior de leitores. Inclusive, coloca a RAC como periódico com maior capilaridade, pois atinge temáticas distintas dentro da área. Além disso, a medida de centralidade ponderada que utilizamos captura como a frequência de citações e a centralidade do periódico que os cita estão imbricados, reforçando o papel da RAC na disseminação do conhecimento dentro das áreas de administração, contabilidade e turismo. Assim, mesmo ela hoje tendo menor impacto que outra revista, é inegável que a esfera de influência da RAC é maior que a das demais revistas da área.

A razão de tal centralidade emergir, a nosso ver, não é somente devido à concepção de qualidade acadêmica que ela conseguiu construir, mas também porque a RAC, a exemplo dos EnANPADs, sempre foi um periódico que serve a múltiplas áreas temáticas, o que favorece seu amplo espectro de citações. Inegavelmente, a RAC, em termos de conhecimento produzido no país pela comunidade brasileira de administração, configura-se como o periódico de maior impacto acadêmico, tanto em termos de resultados quanto em termos de amplitude. Basta agora tentar desdobrar quais seriam os impactos sociais de sua produção.

\section{Impacto social?}

Apesar de a ciência ser um campo com lógica própria, é inegável que outros campos nos quais ela está inserida exercem pressão em definir quais temas ou problemas são dignos de investigação. Com efeito, ter uma lógica própria não necessariamente implica ter total autonomia, até porque a ciência não é autossuficiente, pois depende de recursos que são disponibilizados por atores do campo político, econômico e societário. Isso leva a ciência a sofrer pressões exógenas, exigindo que ela seja mais responsiva em termos do impacto dos seus produtos para além do campo científico. Afinal, não é porque 
a ciência possui um ethos próprio (Merton, 1996) que ela deixará de ser influenciada por prioridades da sociedade (Wilson, Procheş, Braschler, Dixon, \& Richardson, 2007).

Em poucas palavras, a preocupação vai além da qualidade da pesquisa em si, mas se ela também é útil. Preocupação legítima, pois um dos objetivos da ciência é melhorar a vida das pessoas (Smith, 2001). Isso inclusive é válido para a pesquisa em administração. Todavia, o problema fundamental sempre foi definir como avaliar o efeito da pesquisa na sociedade (Grieco, Michelini, \& Iasevoli, 2015). Para ajudar a responder essa pergunta, emergiu, nos últimos anos, uma intensa discussão acerca do impacto social da pesquisa (Rawhouser, Cummings, $\&$ Newbert, 2019). De tão intensa e presente, podese dizer que o termo já é um chavão, pois não há website de uma escola de negócios ou relatório anual de gestão em que o termo não esteja presente.

Mas por que tamanha ubiquidade somente agora? Não é de hoje que a ciência é cobrada pelos seus resultados, mas, nos tempos atuais, dois movimentos são essenciais, a nosso ver, para compreender a proeminência da ideia de impacto social da pesquisa. Primeiro, o avanço de políticas de pós-verdade, que, por sua vez, por meio da desinformação, colocam em xeque o papel da ciência (Lewandowsky, Ecker, \& Cook, 2017). Segundo, diante do foco contemporâneo na sustentabilidade socioambiental de políticas, projetos e negócios, as avaliações de impacto social (SIA) extrapolaram seus fins, servindo como modelo para o campo científico.

Em relação ao primeiro ponto, alguns autores entendem que vivemos em uma era de pós-verdade (Lewandowsky et al., 2017; Lockie, 2017; Sismondo, 2017). Tal era é caracterizada pelo descompasso entre mensagens, normalmente disseminadas em redes sociais, e os fatos que as sustentam (Sismondo, 2017). E, mesmo diante de nenhuma evidência de que tais mensagens sejam verdade, uma massa de indivíduos acredita que tais mensagens falsas sejam verdadeiras porque estão de acordo com suas crenças e interesses (Lockie, 2017). O oposto também é verdade: muito daquilo que é efetivamente fato é tido como inverídico porque não se adequa às crenças de determinada audiência. Consequentemente, como a ciência trabalha com fatos que frequentemente desagradam crenças instituídas, ela acaba virando alvo de grupos de pessoas que buscam desacreditá-la. Para sua defesa, cientistas criam meios de justificar suas atividades, sendo um deles a defesa do seu impacto social.

No que se refere ao segundo ponto, a ideia de "avaliação de impacto social refere-se a avaliar ... uma ampla gama de impactos ... que provavelmente serão experimentados por uma gama igualmente ampla de grupos sociais como resultado de algum curso de ação" (Freudenburg, 1986, p. 452). Como muito da avaliação do impacto social (SIA) remete a se avaliar os desdobramentos de políticas orientadas a partir de pesquisas sociais, o campo da ciência e o campo da avaliação do impacto de políticas sociais se aproximaram, dando forma, ao mesmo tempo, a uma nova área de pesquisa e a um objetivo a ser perseguido: o impacto social (Becker, 2001). Por sua vez, como as preocupações socioambientais são cada vez mais recorrentes em qualquer atividade, incluindo a atividade científica (Grieco et al., 2015), a cobrança se materializou em formas de se mensurar o impacto social da pesquisa (Smith, 2001).

Falar de impacto social da pesquisa não remete somente aos benefícios da pesquisa para um público externo. Remete também a formas de interação entre o meio acadêmico e os demais stakeholders, independentemente de tal contato ser direto ou não (Molas-Gallart \& Tang, 2011). Assim, o impacto social da pesquisa vai além da atividade direta do pesquisador, pois pode ser mediada por qualquer produto criado por ele (Molas-Gallart \& Tang, 2011). Mais ainda, pode-se considerar que a pesquisa impacta socialmente quanto ela possibilita que os stakeholders compreendam a realidade e as consequências de suas ações, permitindo que eles antecipem medidas corretivas (Burdge, 2002). O grande desafio é como criar mecanismos para mensurar atividades que são espaciotemporalmente dispersas (Aguinis, Ramani, Alabduljader, Bailey, \& Lee, 2019; Butler et al., 2017; Pulido, Redondo-Sama, Sordé-Martí, \& Flecha, 2018; Sugimoto et al., 2017).

Em determinadas áreas do conhecimento com maior orientação tecnológica, as ditas 'hard sciences', certos resultados são mais evidentes, tais como a exploração econômica de patentes oriundas da parceria entre universidades e empresas (Moed \& Halevi, 2015) e a criação de produtos e softwares (Smith, 2001). Todavia, em campos científicos tidos como 'soft sciences', em que os produtos da ciência são menos tangíveis, como os da administração, reside o desafio de explorar quais são as diferentes alternativas e formas pelas quais as pesquisas científicas impactam a prática profissional, os debates políticos e públicos e a sociedade em geral (Lima \& Wood, 2014). Smith (2001) aponta para algumas alternativas que vão além de produtos, aplicativos e intervenção direta. O autor adiciona mais quatro dimensões para se avaliar o impacto social da pesquisa, todas úteis, a nosso ver, para a pesquisa em administração: (1) dar publicidade à pesquisa; (2) produzir conteúdo analítico; (3) atividades de ensino; (4) participação em conselhos e comitês. 
Em relação à primeira dimensão, tornar a pesquisa pública, uma das principais revoluções na amplificação do impacto da ciência no âmbito de periódicos deu-se a partir da transição e de seu surgimento na internet. A entrada de periódicos na internet permitiu a ampla divulgação de artigos acadêmicos; antes, o acesso era restrito muitas vezes apenas às bibliotecas de universidades ou institutos de pesquisa. Embora o impacto por meio das citações atreladas às bases científicas tenha sido uma das atenções centrais do debate acadêmico nas últimas décadas, recentemente os pesquisadores têm discutido o papel das mídias e redes sociais na visibilidade e disseminação de periódicos, tornandose uma das fontes de mensuração do impacto social das pesquisas (Butler et al., 2017; Sugimoto et al., 2017). Nesse intuito, o termo Altmetrics tem sido utilizado para representar o campo de investigação interessado em compreender as várias formas e meios de disseminação da comunicação científica nas mídias sociais, permitindo uma maior diversidade e transparência a respeito do uso e interesse dos conhecimentos científicos produzidos.

Ao revisarem a literatura sobre Altmetrics, Sugimoto, Work, Larivière e Haustein (2017) identificaram diversas plataformas pelas quais o conhecimento científico pode ser disseminado, tais como redes sociais, blogs, vídeos, enciclopédias eletrônicas, entre outros meios. Apesar de a maioria das pesquisas ter foco no uso por parte dos pesquisadores, alguns estudos já têm sido realizados para investigar a presença de periódicos em redes sociais (Pulido et al., 2018; Sugimoto et al., 2017). Em especial, o campo da medicina tem se destacado por ações de promoção e divulgação de conhecimento das pesquisas. Com o uso de dados do Journal of the American College of Radiology (JACR), Hawkins, Hillman, Carlos, Rawson, Haines e Duszak (2014) mostraram, por exemplo, que a promoção das pesquisas publicadas pelo journal no Twitter por meio do engajamento com diferentes tipos de usuários aumentou consideravelmente o acesso ao site e visualizações dos artigos publicados.

Em relação à segunda dimensão, produção de conteúdo analítico, não é de hoje que pesquisadores de diferentes áreas, inclusive da administração, produzem livros-texto, estudos de caso, relatórios técnicos, material de ensino, diagnósticos de consultoria e tutoriais de pesquisa. Todos esses materiais nitidamente se configuram como produção de impacto que extrapola a academia, tendo efeito em uma ampla gama de stakeholders (Molas-Gallart \& Tang, 2011; Smith, 2001). O problema é que tal tipo de produção dificilmente é mensurado como atividade relacionada à pesquisa, sem contar que esses materiais podem ser sigilosos.
Deve-se mencionar que o impacto não se reduz à produção, mas engloba também a influência. Por exemplo, Aguinis et al. (2019) se debruçaram em compreender maneiras mais plurais de analisar o impacto das pesquisas acadêmicas. Ao analisarem as referências dos 38 livros mais utilizados no nível de graduação em diversas áreas da administração, os autores identificaram que as referências mais citadas advêm principalmente de fontes acadêmicas oriundas de artigos publicados em periódicos, mais do que revistas, livros e outras fontes. Além disso, outra conclusão relevante do estudo foi que não há uma relação entre o impacto do periódico e a quantidade de citações recebidas pelos periódicos nos livros, demonstrando que embora alguns periódicos possam ter menor fator de impacto (acadêmico), podem ter maior impacto em outros âmbitos, como o do ensino na graduação (social), e vice-versa.

No que se refere à terceira dimensão, atividades de ensino, é impossível negar que muito do conteúdo produzido por pesquisadores é material de ensino, pois se deve notar que elas não se reduzem a atividades de docência. O que se advoga é que os periódicos, inclusive, possam ter um papel preponderante em tais atividades. Tanto que é extremamente comum alguns periódicos, inclusive os de administração, publicarem casos de ensino e, mais recentemente, artigos tutoriais, que são de extrema utilidade para professores. Tais materiais são essenciais em termos de impacto na docência, já que há evidências de que casos e tutoriais facilitam o uso de estratégias ativas de aprendizagem, que, por sua vez, podem aumentar o desempenho de estudantes (Sinnayah, Rathner, Loton, Klein, \& Hartley, 2019).

Por fim, em relação à quarta dimensão mencionada por Smith (2001), a participação em conselhos e comitês remete a uma lógica de atuação das universidades como 'atividades do terceiro fluxo', ou seja, o uso, aplicação e exploração do conhecimento fora do setor universitário (Lockett, Wright, \& Wild, 2015). Como a administração é uma ciência soft, tais atividades remetem muito à participação de pesquisadores como gestores, conselheiros ou consultores, especialmente devido à expertise em gestão que professores da área possuem. Já para periódicos, é mais improvável tal papel.

Como visto, é inegável o valor das atividades de impacto social da pesquisa, desde que elas não comprometam sua integridade. Mas como tais atividades operam em múltiplos níveis e dimensões (Adler \& Harzing, 2009), é extremamente difícil ter indicadores para medi-las de forma confiável. Isso pode contribuir, em parte, para que a busca por impacto social seja considerada, por 
alguns, como uma atividade de segundo escalão da ciência. Como ressalta Mau (2020), o processo de quantificação é um meio de valorização das atividades, pois força comparações entre os atores, forçando-os à competição. Consequentemente, medir tais atividades pode transformar diferenças qualitativas em diferenciação quantitativa, criando uma hierarquização de status. Algo que ainda não ocorre de forma sistemática com o impacto social, diferentemente do impacto acadêmico.

\section{Pensando no impacto social da RAC}

Os periódicos são um meio de comunicação científica, o que restringe, e muito, suas ações de impacto social. Todavia, apesar de tais restrições, algumas das ações de impacto são reproduzidas por meio de periódicos, o que permite sua avaliação, mesmo perante todas as limitações de quantificação de tais medidas de impacto. Logo, diante da ausência de ranqueamento de medidas confiáveis de impacto social de periódicos, nós focaremos nas ações de impacto social da RAC.

Primeiro, em relação às ações da RAC em tornar sua pesquisa pública, recentemente foi visto um grande empenho por parte do atual editor-chefe e da Anpad em criar mecanismos para aumentar a disseminação daquilo que é produzido na RAC. Além da reformulação do site e da construção de uma versão em inglês, houve um esforço intenso de incorporar métricas de 'altmetria' no site, particularmente por meio da incorporação do PlumX Metrics (https://plumanalytics.com/learn/aboutmetrics/ recuperado em 27 de abril de 2020). Isso demonstra o interesse da RAC em capturar o impacto de suas publicações além das citações, na intenção de compreender como elas são disseminadas em redes sociais, blogs, bases e repositórios.

Outra ação que a RAC tinha de disseminação da pesquisa, que aparentemente foi descontinuada, era uma página com seu perfil no Facebook (https:// www.facebook.com/tac.periodicos; recuperado em 27 de abril de 2020). Em tal página, além de notícias sobre lançamento de novas edições, muitas das postagens se referiam a tentativas de tornar a comunicação científica mais palatável para o grande público, utilizando-se de infográficos a vídeos. Inclusive, alguns artigos chegaram a ter um tratamento jornalístico para serem mais facilmente compreendidos pelo público não acadêmico. Apesar de não ser prática corrente dos periódicos nacionais, ter o apoio de jornalistas científicos para dar aos textos um tom menos técnico tornou-os mais atrativos para estudantes, facilitando o aprendizado (Galvão, Felicio, Ferreira, \& Noll, 2020). Deve-se mencionar também que a RAC vem buscando outras formas complementares de divulgação de material relacionado aos artigos, como postar apresentações e outros recursos em plataformas como Zenodo (https://zenodo.org/ recuperado em 27 de abril de 2020) e Mendeley (https://data.mendeley.com/ recuperado em 27 de abril de 2020).

O segundo conjunto de ações de impacto da RAC remete à disseminação de conteúdo analítico que vai além dos artigos científicos tradicionais. Duas iniciativas extremamente relevantes conduzidas pela RAC devem ser mencionadas aqui. Uma é a publicação de artigos tecnológicos. Segundo Motta (2017), tal produção tecnológica busca fazer uma ponte entre acadêmicos e praticantes, cuja abordagem predominante é a solução de problemas, não a sua profunda compreensão. A outra é o engajamento recente da RAC em estimular a produção de artigos tutoriais. Como apontam Martins e Mendes-da-Silva (2020), "os Artigos-Tutoriais deverão abordar e auxiliar pesquisadores, iniciantes e experientes, a executar e implementar, de forma objetiva, aspectos e técnicas empíricas relevantes a uma pesquisa científica em Administração" (Martins $\&$ Mendes-da-Silva, 2020, p. 272).

A terceira ação de impacto da RAC, que se refere à produção de material de suporte ao ensino, é o espaço dado à publicação de casos de ensino. Como apontaram Faria e Figueiredo (2013), a demanda por métodos participativos de ensino, inclusive de casos, vem crescendo na área de administração. Mesmo não sendo uma estratégia nova, é inegável o impacto dos casos na educação executiva, sem contar que tal material, que exige grande esforço de produção, permite que professores, um dos principais stakeholders do conhecimento científico, utilizem de material prático de alta qualidade sem ter que o produzir. Em termos educacionais, deve-se destacar que conteúdos analíticos como artigos tecnológicos e tutoriais também podem ser utilizados como material de ensino, especialmente na pós-graduação. Soma-se a esses dois tipos de documentos a recente iniciativa da RAC em instituir uma política de dados, materiais e códigos abertos (Mendes-da-Silva, 2019), pois os estudantes podem usar tais bases para treinamento em técnicas analíticas.

Por fim, a quarta ação de impacto social da RAC e, a nosso ver, a mais intangível de todas, é a importância do periódico, com sua proposta acadêmica, em mudar a forma de pensar sobre a gestão pública e privada. A gestão, em qualquer lugar, tende a ser voluntarista, o que faz com que o empirismo seja a regra, não a análise sustentada em dados. Então, a nosso ver, sendo a RAC o periódico que representa a academia brasileira em administração, é necessário pensá-la como símbolo de mudança cultural acerca das práticas de gestão no país. Frases do tipo 'é o olho do dono que engorda 
o gado' ou até 'manda quem pode, obedece quem tem juízo', por mais que sejam comprovadamente enganosas do ponto de vista da sua eficácia, ainda têm espaço no meio prático porque o conhecimento acadêmico sobre gestão não é levado tanto a sério. E isso precisa mudar.

\section{ESTABELECENDO UMA IDENTIDADE PARA A RAC}

Como destacamos desde o início do artigo, resgatamos elementos distintivos da Revista de Administração Contemporânea (RAC) em sua gênese. Cabe agora tentar estabelecer uma identidade para a RAC considerando todos esses elementos. Para tanto, assumimos que um periódico pode ser compreendido como uma organização. Isso nos permite pensar, primeiramente, que a identidade de um periódico, assim como de organizações, remete àquilo que é central, distinto e duradouro (Albert \& Whetten, 1985). O que faz todo sentido, pois há boas razões para se buscar uma identidade distintiva para um periódico (Faems et al., 2016). Em segundo lugar, se o periódico tem uma identidade, ela é construída considerando quatro aspectos. Primeiro, que a identidade reflete aspectos culturais do contexto em que uma entidade está imersa (Hatch \& Schultz, 2002). Segundo, que ela emerge a partir da interação com seus stakeholders (Scott \& Lane, 2000). Terceiro, que a projeção da identidade para o contexto externo remete à tipificação de um papel perante a comunidade (Ashforth, 2001), cujo exercício leva à construção de uma imagem (Hatch \& Schultz, 2002). Quarto, e como ponto central para o nosso argumento, que as características estabelecidas no nascimento deixam uma impressão duradoura na identidade (Kroezen \& Heugens, 2012; Marquis \& Tilcsik, 2013).

Cabe mostrar se tais aspectos são duradouros de fato. Fizemos isso demonstrando que os elementos centrais no período de fundação da RAC ainda estão presentes. Primeiro, nós verificamos se os aspectos ligados à lógica acadêmica pertencente aos resumos dos artigos da RAC em 1997 (ver Figura 2) apresentavam uma trajetória duradoura. Para tanto, avaliamos a frequência dos seis termos analisados em 1997 (análise, estudo, pesquisa, teoria, método, empírico) até o ano de 2020. A Figura 5 ilustra a trajetória de ocorrência de termos ano a ano. Como pode ser visto, há durabilidade nos termos, com variações pontuais. A frequência média de cada um acompanha os rótulos na legenda. Dos seis termos, o único que apresentou variação significativa no período foi estudo $\left(\chi^{2}=40,56\right.$, $p<0,05)$; nenhum dos demais apresentou variação significativa. Isso demonstra que, apesar dos mais de 20 anos de fundação do periódico, os elementos relacionados à ciência continuam textualmente presentes nos resumos dos artigos, em proporções similares às do nascimento da RAC.

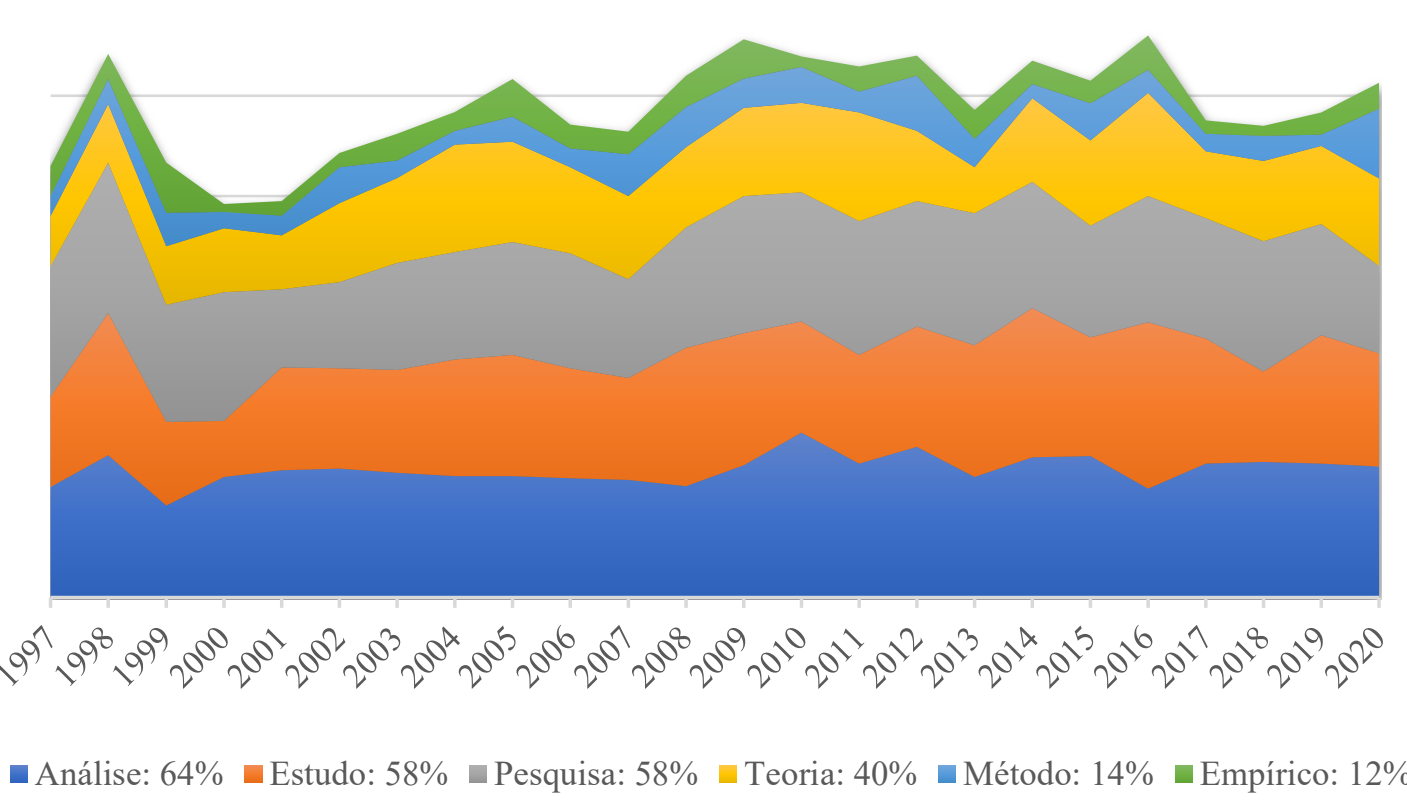

Figura 5. Trajetória de ocorrência de termos que remetem à pesquisa na RAC (1997-2020).

Termos capturados nos resumos de 934 artigos publicados de 1997 a 2020 pelas RAC. Documentos sem resumo foram excluídos. Na legenda de cada termo, apontamos a frequência média no período. Termos que foram compostos por mais de uma palavra: teoria (conceito, teoria, teórico ou teoricamente); empírico (empírico ou empiricamente); análise (análise, analisar ou analítico); pesquisa (pesquisa, pesquisar ou verificar). 
Depois, reproduzimos, com dados de 2019, a comparação dos termos referentes à lógica científica nos resumos dos artigos publicados em 1997 (Figura 2), mas com dados recentes, de 2019. Comparamos a frequência dos termos na RAC com RAP, O\&S, RAE e com os demais periódicos presentes no Spell. A Rausp teve que ser descartada porque não possuía resumos em português cadastrados na base do Spell. A frequência cruzada de cada um dos termos com cada um dos periódicos está no mapa de calor da Figura 6. O padrão de frequência de termos na
RAC é muito similar ao do ano de 1997: os termos pesquisa (55,6\%), análise (66,7\%) e estudo $(63,9 \%)$ mostrando alta frequência, assim como os termos teoria $(38,9 \%)$ e empírico $(11,1 \%)$ com frequência alta em relação aos demais. Assim como em 1997, a presença conjunta de termos relacionados à teoria e à pesquisa empírica ressalta que a RAC buscou, até os dias atuais, ser um periódico que concilia esses dois elementos. Isso é importante porque, apesar do tempo, é uma característica que a diferencia dos demais.

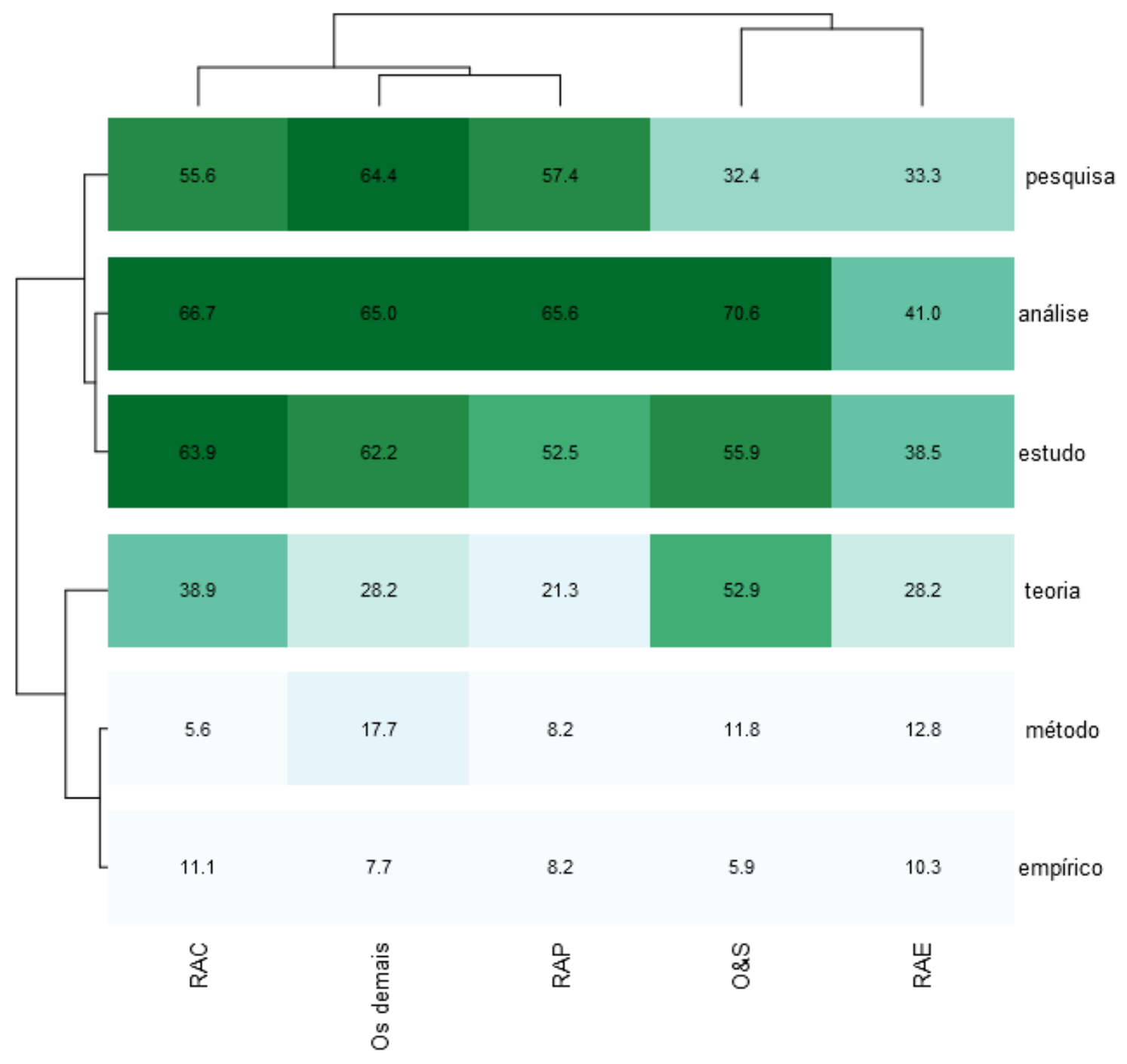

Figura 6. Coocorrência de termos que remetem à pesquisa (ano de 2019).

Termos capturados nos resumos de 2.978 artigos publicados em 2019 pelos quatro periódicos e pela média de todos os outros. 114 periódicos analisados no total. A Rausp foi excluída porque não apresenta resumos em português na base do Spell. Documentos sem resumo em português foram ignorados. Células remetem à frequência de artigos que mencionaram cada termo. Termos que foram compostos por mais de uma palavra: teoria (conceito, teoria, teórico ou teoricamente); empírico (empírico ou empiricamente); análise (análise, analisar ou analítico); pesquisa (pesquisa, pesquisar ou verificar).

Legenda: Revista de Administração Contemporânea (RAC); Organizações \& Sociedade (O\&S); Revista de Administração Pública (RAP); Revista de Administração de Empresas (RAE). 
Outro ponto importante que deve ser destacado é como os demais periódicos, cuja grande maioria é recente e com menor avaliação no Qualis Capes, apresentaram um padrão similar ao da RAC e também da RAP, cuja ênfase em alguns termos foi até maior. Aqui, cabe uma explicação institucionalista: baseando-se em DiMaggio e Powell (1983), na ausência de critérios nítidos de efetividade para os periódicos, processos isomórficos operaram por meio da coerção (avaliação Qualis), da norma (expectativa de autores, revisores e indexadores) e do mimetismo (reproduzindo práticas dos periódicos mais centrais). No entanto, tendo como referência Tolbert e Zucker (1983), como foi um processo de institucionalização relativamente tardio, pois muitos periódicos surgiram em meados dos anos 2000 em diante, muito desse isomorfismo se deu na intenção de legitimar tais periódicos perante sua audiência, não necessariamente com a preocupação de serem efetivos com sua missão ou com seus processos. Apesar de não podermos atribuir o gatilho de tal processo isomórfico à RAC, não dá para negar que seu modelo representava uma lógica acadêmica em ascensão na área de administração.

Por fim, comparamos os padrões de referências da RAC com os dos demais periódicos, cujos resultados estão na Figura 7. Assim como em 1997, a RAC tem uma média de referências por artigo (61,7 referências) bem superior à dos demais periódicos $(42,1)$, demonstrando ainda a preocupação com a fundamentação teóricoempírica. O percentual de citações de produção qualificada (journals) também é maior que a média dos demais (62\% contra $48 \%$ ). E, apesar de tal ênfase em artigos de journals, a RAC não abandonou o uso da produção em periódicos nacionais (7\%), apesar de este ser menor que o dos internacionais (10\%), nem abandonou o uso de livros (17\%), cujo uso, em muitos casos, remete a preocupações com o aprofundamento teórico. Nossa leitura de tal padrão de referências é que, além de rigor acadêmico, a RAC buscou, ao mesmo tempo, diálogo entre produção nacional e estrangeira e conciliação da teoria com a pesquisa empírica. $\mathrm{O}$ que, novamente, ressalta seus traços já marcados em sua fundação.

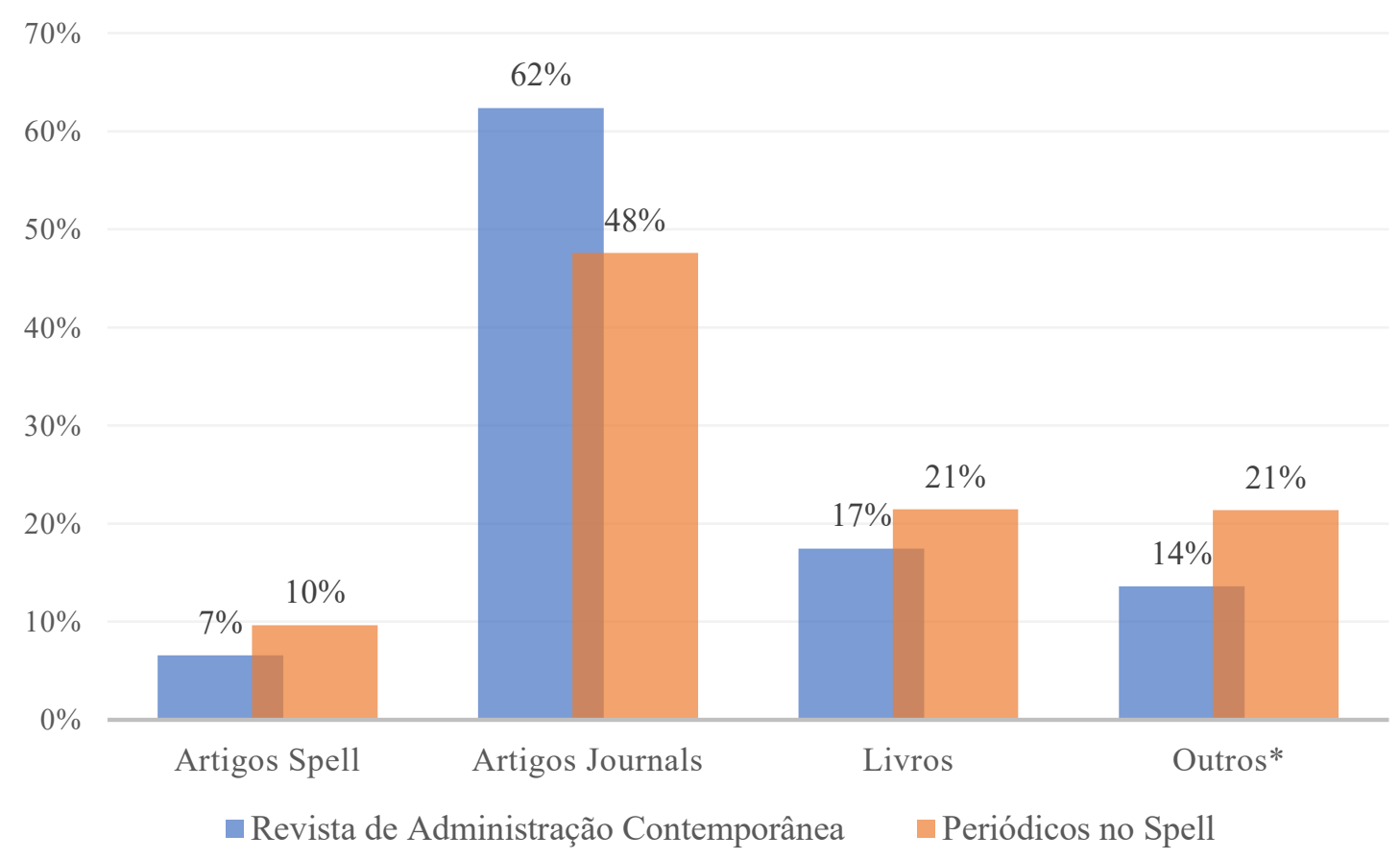

Figura 7. Tipos de documentos referenciados pelos artigos do Spell publicados em 2018.

Dados coletados no Spell, ano de 2018. Média de referências por artigo: 42,1 referências; RAC: 61,7 referências. *Demais tipos de documentos referenciados: capítulo de livro; caso de ensino; dissertação; editorial; genérico; matéria de jornal; matéria de revista; monografia; nota bibliográfica; outro; relatório; resenha; resumo de teses ou dissertações; tese; web; working paper. 
Para sacramentar o argumento de que o contexto de fundação da RAC marcou sua identidade, além de demonstrá-lo empiricamente, faltava verificar se o discurso oficial da revista era coerente com o da fundação. E o discurso atual da RAC em seu site, mais de 20 anos depois de sua criação, não deixa dúvidas:

\section{A partir de uma perspectiva regional e espírito interdisciplinar, a RAC está posicionada na vanguarda da inovação teórica e metodológica, dando boas-vindas a contribuições substantivas e empíricas, que investigam e problematizam questões significativas de preocupação econômica, social e política, especialmente onde essas novas abordagens avançam. Priorizamos o trabalho empiricamente engajado, e que promove abordagens epistemológicas críticas, que ampliem os limites conceituais, e coloque a teoria para atuar de maneiras inovadoras, e que navega conscientemente pelas políticas de produção de conhecimento, dentro e fora da academia (Revista de Administração Contemporânea, n.d., n.p., grifo no original).}

Em essência e substância, o que é posto hoje no site da RAC reproduz sua missão instituída em 1997. Com exceção do termo regional, que, em nossa análise, nunca figurou como um elemento distintivo do periódico. Então, a avaliação que empreendemos aqui aponta que a gênese, impacto e trajetória da RAC constituíram, como elemento central e distintivo de sua identidade, o papel de periódico generalista da academia brasileira em administração, cuja concepção de ciência remete ao rigor analítico fortemente fundamentado na interdependência entre teoria e pesquisa empírica. E vale ressaltar que a identidade da RAC é indissociável da própria identidade da Anpad enquanto comunidade acadêmica, pois, como bem apontou um de seus expresidentes, "a atividade científica e a comunicação científica são indissociáveis" (Guimarães et al., 2018, p. 526).

É claro que a identidade da RAC não se reduz a esses elementos, pois vários outros se manifestaram em sua trajetória como distintivos. Então, respeitando a natureza multifacetada da identidade, mas também de coerência intertemporal dos demais elementos, destacamos cada um deles que se manifestaram em nossa análise:

1. A RAC é o periódico que representa a academia brasileira em administração, cuja consolidação confunde-se com a própria história de consolidação da área;

2. É um periódico que reflete uma concepção generalista e interdisciplinar da gestão e das organizações, dando espaço aos diferentes eixos temáticos que compõem a disciplina no país;

3. A RAC nasceu para ser grande, com centralidade local e forte influência na disseminação do conhecimento no campo da administração do Brasil;

4. Sempre foi um periódico crítico ao gerencialismo, prezando pela profundidade teórica, rigor metodológico e relevância acadêmica. O que remete a ser um periódico pautado na crítica científica, seja por meio de estudos teóricoempíricos, seja por meio de ensaios;

5. É um periódico genuinamente brasileiro, preocupado com problemas brasileiros, o que não exclui o aporte de autores estrangeiros, nem iniciativas de internacionalização;

6. É independente de qualquer instituição de ensino superior, preza pela diversidade regional de autorias e vai contra conflitos de interesse na publicação, em particular, a endogenia;

7. Tem uma lógica de avaliação consolidada, com ampla participação da comunidade acadêmica, que preza pelo rigor, qualidade e imparcialidade;

8. Sempre buscou a inovação em conteúdo e em processos editoriais, sendo receptiva a novos formatos de publicação e a novas tecnologias de comunicação científica;

9. Apesar de não ser mencionado ainda, é um periódico de acesso aberto, ao encontro da tradição brasileira de garantir que o acesso ao conhecimento seja livre. Isso implica, inclusive, defender política de ampla abertura de dados e documentos complementares, bem como defender a máxima transparência possível no processo editorial.

\section{Implicações acerca da identidade da RAC}

Toda constituição de identidade remete ao exercício de um papel perante sua comunidade. Diante disso, ao invés de discutir sobre implicações teóricas e práticas, como um estudo qualquer, apontamos algumas implicações acerca das consequências, bem como das ações que a RAC deveria refletir acerca do exercício de sua identidade. Claro que essa não é necessariamente a visão do corpo editorial do periódico, nem da diretoria de sua mantenedora, mas ela reflete a análise daquilo que foi distintivo na trajetória da RAC. O que delineamos aqui é uma concepção de futuro da RAC, que, a nosso ver, em parte, já se faz presente. 
Em primeiro lugar, enfatizamos que a RAC possui uma identidade científica que preza pelo rigor teórico, metodológico e empírico. A nosso ver, isso está já consolidado nos artigos acadêmicos da revista, apesar de não termos certeza de que o corpo de avaliadores internalizou tal identidade. Mas o que queremos ressaltar é que essa lógica também deve estar presente nos demais documentos que a RAC publica. Casos de ensino, artigos tecnológicos e artigos tutoriais devem passar pelo mesmo crivo de exigência teórico-conceitual que os artigos acadêmicos, pois não é porque o formato e o objetivo sejam diferentes que devem ser colocados de lado aspectos essenciais da concepção de um produto científico. Caso contrário, tais produtos poderiam descaracterizar a identidade da RAC.

Em segundo lugar, entendemos que a política de ciência aberta recentemente instituída pela RAC (ver Mendes-da-Silva, 2019), que implica a adoção de política de abertura de acesso, dados, materiais, códigos, contribuições dos autores e avaliação (Martins, 2020), deve ser amplamente adotada e disseminada. Primeiramente, porque isso é um importante movimento para tornar a pesquisa mais transparente e replicável, tanto que periódicos importantes da área, como o Journal of International Business Studies, promoveram recentemente mudanças em sua política editorial (Beugelsdijk, Witteloostuijn, \& Meyer, 2020), incorporando uma abordagem de data access and research transparency (DART). Segundo, porque tal política de transparência e de dados abertos pode mitigar o viés de publicação, em que resultados inconclusivos ou negativos são propositalmente obliterados do processo, colocando luz sobre o que Petty, Stephenson e Hadley (2019) chamam de Dark Data: dados que apontam para resultados negativos ou que refutariam os dados presentes na publicação. A adoção de tais políticas merece, inclusive, pensar na revisão do Manual de Boas Práticas da Publicação Científica da Anpad, importante peça normativa acerca da ética da pesquisa em nossa área.

Em terceiro lugar, a RAC deve enfatizar a sua natureza 'glocal' - global mais local -, em que aspectos relacionados à lógica internacional de produção científica são conciliados com as características e idiossincrasias da produção do conhecimento nacional sobre gestão. Algo que já foi mencionado por Alcadipani e Rosa (2011), mas que trouxemos para o contexto de delimitação do papel de um periódico. Como dito, a RAC é um periódico central e relevante no Brasil e sua força reside aí, pois temos uma grande comunidade no país. Mas para que ela cresça e tenha a representatividade que merece, ela precisa lidar com o jogo global da comunicação científica, em que ela é ainda um ator periférico.
Isso não significa mimetizar o modelo publish or perish global. Como aponta Alcadipani (2017), na medida em que "a tentativa das pessoas dos países do Sul de copiar as lógicas de funcionamento dos países do Norte sem ter a mesma base social, cultural e econômica ... produzimos uma cópia malfeita que não traz benefícios para nós mesmos" (Alcadipani, 2017 , p. 407). Sem contar que os benefícios de copiar tal lógica não sejam evidentes. Por exemplo, Rosa e Romani-Dias (2019) observaram que periódicos nacionais em bases internacionais apresentaram baixo desempenho em termo de impacto quando realizaram a transição para o inglês. Os autores apontam que, além de serem pouco citados nessas bases, seus impactos são originados muitas vezes de autocitações ou de citações de autores brasileiros que publicam em periódicos internacionais. Outro receio observado por periódicos ao se adotar a língua inglesa como modelo de comunicação tem sido a perda de visibilidade e de impacto dos artigos no próprio país de origem. Rossoni (2018a), por exemplo, defende a manutenção da língua portuguesa como forma de garantir a legitimidade e o impacto dos periódicos em sua própria língua de origem, pois eles tendem a ser mais acessados, baixados e citados.

Em termos práticos, para satisfazer a busca pela internacionalização e, ao mesmo tempo, não perder a disseminação de conhecimento no país de origem, nosso entendimento é de que a RAC deva enfatizar o modelo de publicação bilíngue, no qual o mesmo artigo é publicado nas versões em português e inglês. Tal modelo tem sido adotado como prática por outros periódicos e tem possibilitado a visibilidade dos artigos e amplo acesso aos acadêmicos brasileiros, ao mesmo tempo que busca projetar as publicações para o público internacional (Nassif, 2019; Tonelli, 2019). Outra ação que vem sendo colocada em prática na RAC é a realização de chamadas especiais, em que há participação de autores estrangeiros, que trazem expertise e visibilidade para o periódico, sem descaracterizar sua lógica local. Pesquisadores como Diniz (2017) e Rosa e Romani-Dias (2019) apontam para os desafios dessa estratégia na atração de autores estrangeiros consagrados como forma de dar visibilidade e legitimidade aos periódicos nacionais no contexto global.

Sabemos que tais ações podem levar ao risco de haver alguma sobreposição com a Brazilian Administration Review (BAR), que nasceu como projeto de internacionalização da produção da Anpad. Todavia, a nosso ver, para que a RAC continue grande e central, como ela é no cenário nacional, não há muita alternativa a não ser também se impor no cenário internacional desde que respeite a sua essência local. 
Em quarto e último lugar, é essencial que a RAC avance em seu projeto de internacionalização, marcando presença nos dois grandes indexadores internacionais: Scopus e Web of Science. Mesmo os periódicos brasileiros tendo a grande maioria de suas citações originada de periódicos nacionais ou de regiões mais periféricas, cujos citantes têm também impacto baixo (Rossoni, 2018a), não se pode descartar que pesquisadores internacionais, e mais do que nunca, nacionais, consideram como condição a presença em tais bases, numa ou noutra, para publicar. E, olhando para a posição que a RAC possui nacionalmente e internacionalmente, se comparada aos demais periódicos brasileiros da área, é injustificável que ela não esteja em ambas as bases. Sabemos que não depende somente do corpo editorial e da direção da Anpad o aceite em tais bases, mas isso tem que ser encarado enquanto projeto de área, como já articulado em iniciativas anteriores em nosso campo acadêmico (Kimura, Carneiro, Alperstedt, \& Neto, 2014), não somente do periódico. Afinal, se há um periódico que representa o campo da pesquisa em administração no país, esse periódico é a Revista de Administração Contemporânea.

\section{CONCLUSÃO}

Neste artigo, evidenciamos a formação da identidade da Revista de Administração Contemporânea (RAC) a partir da ideia de impressão organizacional. Para tanto, buscamos aquilo que era distintivo desde a sua gênese, que foi fortemente influenciada pelo contexto político e social de consolidação da Associação Nacional de PósGraduação e Pesquisa em Administração (Anpad). Os depoimentos, textos históricos e dados analisados apontaram que o elemento central e distintivo de sua identidade é sua posição como principal periódico generalista da academia brasileira em administração, cuja concepção de ciência remete ao rigor analítico fortemente fundamentado na interdependência entre teoria e pesquisa empírica. Verificamos a eficácia da construção de tal identidade por meio da análise do impacto científico e social do periódico na comunidade brasileira de administração, o que nos levou a afirmar que a RAC é o periódico acadêmico mais influente e central da área. Por fim, apontamos algumas implicações acerca da identidade construída da RAC, identificando alguns cursos de ações futuras.

\section{NOTA DE FIM}

1. A entrevista concedida pelo professor Tomas de Aquino Guimarães foi realizada por meio de videoconferência em 29 de fevereiro de 2020. As interpretações acerca dos fatos relatados na entrevista são de inteira responsabilidade dos autores.

\section{REFERÊNCIAS}

Adler, N. J., \& Harzing, A. W. (2009). When knowledge wins: Transcending the sense and nonsense of academic rankings. Academy of Management Learning \& Education, 8(1), 72-95. https://doi.org/10.5465/ amle.2009.37012181

Aguinis, H., Ramani, R. S., Alabduljader, N., Bailey, J. R., \& Lee, J. (2019). A pluralist conceptualization of scholarly impact in management education: Students as stakeholders. Academy of Management Learning \& Education, 18(1), 11-42. https://doi.org/10.5465/amle.2017.0488

Aguinis, H., Shapiro, D. L., Antonacopoulou, E. P., \& Cummings, T. G. (2014). Scholarly impact: A pluralist conceptualization. Academy of Management Learning \& Education, 13(4), 623-639. https://doi.org/10.5465/ amle.2014.0121

Aguinis, H., Suárez-González, I., Lannelongue, G., \& Joo, H. (2012). Scholarly impact revisited. Academy of Management Perspectives, 26(2), 105-132. https://doi.org/10.5465/ amp.2011.0088

Alcadipani, R. (2017). Periódicos brasileiros em inglês: A mímica do publish or perish "global". Revista de Administração de Empresas, 57(4), 405-411. http:// dx.doi.org/10.1590/s0034-759020170410
Alcadipani, R., \& Rosa, A. R. (2011). From grobal management to glocal management: Latin american perspectives as a counter-dominant management epistemology. Canadian Journal of Administrative Sciences, 28(4), 453-466. https://doi.org/10.1002/cjas.165

Albert, S., \& Whetten, D. A. (1985). Organizational identity. In B. M. Staw \& L. L. Cummings (Eds.), Research in Organizational Behavior (pp. 263-295). Greenwich, CT: JAI Press.

Ashforth, B. (2001). Role transitions in organizational life: An identity-based perspective. Abingdon: Routledge.

Ashforth, B. E., \& Mael, F. (1989). Social identity theory and the organization. Academy of Management Review, 14(1), 20-39. https://doi.org/10.5465/amr.1989.4278999

Ashford, S. J. (2013). Having scholarly impact: The art of hitting academic home runs. Academy of Management Learning \& Education, 12(4), 623-633. http://dx.doi. org/10.5465/amle.2013.0090

Becker, H. A. (2001). Social impact assessment. European Journal of Operational Research, 128(2), 311-321. https://doi. org/10.1016/S0377-2217(00)00074-6 
Beugelsdijk, S., Witteloostuijn, A. V., \& Meyer, K. E. (2020). A new approach to data access and research transparency (DART). Journal of International Business Studies. https://doi.org/10.1057/s41267-020-00323-z

Birkinshaw, J., Lecuona, R., \& Barwise, P. (2016). The relevance gap in business school research: Which academic papers are cited in managerial bridge journals?. Academy of Management Learning \& Education, 15(4), 686-702. https://doi.org/10.5465/amle.2015.0282

Bourdieu, P. (1975). The specificity of the scientific field and the social conditions of the progress of reason. Social Science Information, 14(6), 19-47. https://doi.org/10.1 177\%2F053901847501400602

Burdge, R. J. (2002). Why is social impact assessment the orphan of the assessment process? Impact Assessment and Project Appraisal, 20(1), 3-9. https://doi. org/10.3152/147154602781766799

Butler, J. S., Kaye, I. D., Sebastian, A. S., Wagner, S. C., Morrissey, P. B., Schroeder, G. D., \& Vaccaro, A. R. (2017). The evolution of current research impact metrics: from bibliometrics to altmetrics? Clinical Spine Surgery, 30(5), 226-228. https://doi.org/10.1097/bsd.0000000000000531

DiMaggio, P. J., \& Powell, W. W. (1983). The iron cage revisited: Institutional isomorphism and collective rationality in organizational fields. American Sociological Review, 48(2), 147-160. https://doi.org/10.2307/2095101

Diniz, E. H. (2017). Periódicos brasileiros da área de Administração no contexto de internacionalização da produção científica. Revista de Administração de Empresas, 57(4), 357-364. http://dx.doi.org/10.1590/ s0034-759020170406

Fachin, R. C. (2006). Construindo uma associação científica: Trinta anos da ANPAD - memórias, registro, desafios. Porto Alegre: ANPAD.

Faems, D., Filatotchev, I., Harley, B., \& Siegel, D. (2016). The distinctive identity of the Journal of Management Studies. Journal of Management Studies, 53(7), 11091112. https://doi.org/10.1111/joms.12212

Faria, M., \& Figueiredo, K. F. (2013). Casos de ensino no Brasil: Análise bibliométrica e orientações para autores. Revista de Administração Contemporânea, 17(2), 176-197. https://doi.org/10.1590/S1415-65552013000200004

Ferreira, M. P. (2015). Periódicos e rankings de periódicos em administração. Pensamento Contemporâneo em Administração, 9(2), 1-16. https://doi.org/10.12712/ rpca.v9i2.502

Freudenburg, W. R. (1986). Social impact assessment. Annual Review of Sociology, 12(1), 451-478. https://doi. org/10.1146/annurev.so.12.080186.002315

Galvão, T., Felicio, C. M., Ferreira, J. C., \& Noll, M. (2020). Scientific journalism as an educational practice: An experience report of the collective construction of a "science clothesline". Science Communication, 42(2), 265-276. https://doi.org/10.1177/1075547020909467

Garfield E. (1955). Citation indexes to science: A new dimension in documentation through association of ideas. Science, 122(3159), 108-11. https://doi.org/10.1126/ science.122.3159.108
Garfield, E. (2006). The history and meaning of the journal impact factor. Jama, 295(1), 90-93. https://doi.org/10.1001/ jama.295.1.90

Garfield, E., \& Sher, I. H. (1963). New factors in the evaluation of scientific literature through citation indexing. American Documentation, 14(3), 195-201. https://doi. org/10.1002/asi.5090140304

Giampapa, F. (2011). The politics of "being and becoming" a researcher: Identity, power, and negotiating the field. Journal of Language, Identity \& Education, 10(3), 132144. https://doi.org/10.1080/15348458.2011.585304

Grieco, C., Michelini, L., \& Iasevoli, G. (2015). Measuring value creation in social enterprises: A cluster analysis of social impact assessment models. Nonprofit and Voluntary Sector Quarterly, 44(6), 1173-1193. https:// doi.org/10.1177\%2F0899764014555986

Guimarães, T. A., Motta, G. D. S., Farias, S. A. D., Kimura, H., Quintella, R. H., \& Carneiro, J. M. T. (2018). A ANPAD e o processo de institucionalização da comunidade científica brasileira de administração. Cadernos EBAPE. $B R$, 16(spe), 523-537. https://doi.org/10.1590/1679395173273.

Harrison, T. M., \& Stephen, T. D. (1995). The electronic journal as the heart of an online scholarly community. Library Trends, 43(4), 592-608. Retrieved from https://scholarsarchive.library.albany.edu/cas communication_scholar/5/

Harzing, A.-W., \& Van Der Wal, R. (2009). A google scholar hindex for journals: An alternative metric to measure journal impact in economics and business. Journal of the American Society for Information Science and Technology, 60(1), 41-46. https://doi.org/10.1002/ asi.20953

Hatch, M. J., \& Schultz, M. (2002). The dynamics of organizational identity. Human Relations, 55(8), 989-1018. https:// doi.org/10.1177\%2F0018726702055008181

Hawkins, C. M., Hillman, B. J., Carlos, R. C., Rawson, J. V., Haines, R., \& Duszak, R., Jr. (2014). The impact of social media on readership of a peer-reviewed medical journal. Journal of the American College of Radiology, 11(11), 10381043. https://doi.org/10.1016/j.jacr.2014.07.029

Hicks, D., Wouters, P., Waltman, L., De Rijcke, S., \& Rafols, I. (2015). Bibliometrics: The leiden manifesto for research metrics. Nature, 520(7548), 429-431. https://doi. org/10.1038/520429a

Hoffmann, C. P., Christoph L., \& Miriam, M (2014, January). Impact factor 2.0: Applying social network analysis to scientific impact assessment. Proceedings of the Hawaii International Conference on System Sciences, Waikoloa, HI, USA, 47. Retrieved from https://ieeexplore.ieee. org/document/6758799

Immelmann, K. (1975). Ecological significance of imprinting and early learning. Annual Review of Ecology \& Systematics, 6, 15-37. https://doi.org/10.1146/annurev. es.06.110175.000311

Kaur, J., Radicchi, F., \& Menczer, F. (2013). Universality of scholarly impact metrics. Journal of Informetrics, 7(4), 924-932. https://doi.org/10.1016/j.joi.2013.09.002 
Kimura, H., Carneiro, J., Alperstedt, G. D., \& Neto, A. C. (2014). O processo de internacionalização de periódicos nacionais. Revista de Administração Contemporânea, 18(6), 1-3. https://doi.org/10.1590/1982-7849rac2014140090

Kroezen, J. J., \& Heugens, P. P. M. A. R. (2012). Organizational identity formation: Processes of identity imprinting and enactment in the Dutch microbrewing landscape. In M. Schultz, S. Maguire, A. Langley, \& H. Tsoukas. Constructing identity in and around organizations (pp. 89-127). Oxford: Oxford University Press.

Lazzarini, S. (2017). Pesquisa em administração: Em busca de impacto social e outros impactos. Revista de Administração de Empresas, 57(6), 620-625. http:// dx.doi.org/10.1590/s0034-759020170608

Lewandowsky, S., Ecker, U. K. H., \& Cook, J. (2017). Beyond misinformation: Understanding and coping with the "post-truth" era. Journal of Applied Research in Memory and Cognition, 6(4), 353-369. https://doi. org/10.1016/j.jarmac.2017.07.008

Lima, G. M. R., \& Wood, T., Jr. (2014). The social impact of research in business and public administration. Revista de Administração de Empresas, 54(4), 458-463. http:// dx.doi.org/10.1590/S0034-759020140410

Lockett, A., Wright, M., \& Wild, A. (2015). The institutionalization of third stream activities in UK higher education: The role of discourse and metrics. British Journal of Management, 26(1), 78-92. https://doi. org/10.1111/1467-8551.12069

Lockie, S. (2017). Post-truth politics and the social sciences. Environmental Sociology, 3(1), 1-5. https://doi.org/10. $1080 / 23251042.2016 .1273444$

Machado-da-Silva, C. L. (1997a). A associação nacional dos programas de pós-graduação em administração nas palavras de seus presidentes. Revista de Administração Contemporânea, 1(1), 145-173. https://dx.doi. org/10.1590/S1415-65551997000100008

Machado-da-Silva, C. L. (1997b). Editorial. Revista de Administração Contemporânea, 1(1), 1. https://dx.doi. org/10.1590/S1415-65551997000100001

Machado-da-Silva, C. L., Guarido Filho, E. R., Rossoni, L., \& Graeff, J. F. (2008). Periódicos brasileiros de Administração: Análise bibliométrica de impacto no triênio 2005 impacto no triênio 2005-2007. RAC-Eletrônica, 2(3), 351-373. Retrieved from http://www.spell.org.br/ documentos/ver/31030/periodicos-brasileiros-deadministracao--analise-bibliometrica-de-impacto-notrienio-2005--2007/i/pt-br

Marquis, C., \& Tilcsik, A. (2013). Imprinting: Toward a multilevel theory. Academy of Management Annals, 7(1), 195-245. https://doi.org/10.5465/19416520.2013.766076

Martins, H. C. (2020). A importância da ciência aberta (open science) na pesquisa em Administração. Revista de Administração Contemporânea, 24(1), 1-2. https://doi. org/10.1590/1982-7849rac2020190380

Martins, H. C., \& Mendes-Da-Silva, W. (2020). The new section of the Journal of Contemporary Administration: Tutorial articles. Revista de Administração Contemporânea, 24(3), 275-282. https://doi.org/10.1590/19827849rac2020200044
Mau, S. (2020). Numbers matter! The society of indicators, scores and ratings. International Studies in Sociology of Education, 29(1-2), 19-37. https://doi.org/10.1080/096 20214.2019.1668287

Mendes-Da-Silva, W. (2019). Relatório de gestão da Revista de Administração Contemporânea 2018-2019. Revista de Administração Contemporânea, 23(6), 1-10. https:// dx.doi.org/10.1590/1982-7849rac2019190356

Merton, R. K. (1996). The ethos of science. In R. K. Merton (Org.), On social structure and science (pp. 267-276). Chicago: The University of Chicago Press.

Meyer, J. W., \& Rowan, B. (1977). Institutionalized organizations: Formal structure as myth and ceremony. American Journal of Sociology, 83(2), 340-363. https://doi. org/10.1086/226550

Mingers, J., \& Harzing, A. W. (2007). Ranking journals in business and management: A statistical analysis of the Harzing data set. European Journal of Information Systems, 16(4), 303-316. https://doi.org/10.1057/palgrave. ejis.3000696

Moed, H. F., \& Halevi, G. (2015). Multidimensional assessment of scholarly research impact. Journal of the Association for Information Science and Technology, 66(10), 19882002. https://doi.org/10.1002/asi.23314

Molas-Gallart, J., \& Tang, P. (2011). Tracing 'productive interactions' to identify social impacts: An example from the social sciences. Research Evaluation, 20(3), 219-226. https://doi.org/10.3152/09582021 $1 \mathrm{X} 12941371876706$

Motta, G. D. S. (2017). Como escrever um bom artigo tecnológico?. Revista de Administração Contemporânea, 21(5), 4-8. http://dx.doi.org/10.1590/1982-7849rac2017170258

Nassif, V. M. J. (2019). A quem interessa os artigos científicos na área de empreendedorismo? Um dilema sobre o formato e o idioma das publicações. Revista de Empreendedorismo e Gestão de Pequenas Empresas, 8(3), 1-8. http://dx.doi.org/10.14211/regepe.v8i3.1740

Opsahl, T., Agneessens, F., \& Skvoretz, J. (2010). Node centrality in weighted networks: Generalizing degree and shortest paths. Social Networks, 32(3), 245-251. https://doi. org/10.1016/j.socnet.2010.03.006

Petty, S., Stephenson, H., \& Hadley, S. (2019). Shining more light on dark data. Science Editor, 43(1), 7-10. https://doi. org/10.36591/SE-D-4301-7

Pulido, C. M., Redondo-Sama, G., Sordé-Martí, T., \& Flecha, R. (2018). Social impact in social media: A new method to evaluate the social impact of research. PloS one, 13(8), e0203117. https://doi.org/10.1371/journal. pone.0203117

Rawhouser, H., Cummings, M., \& Newbert, S. L. (2019). Social impact measurement: Current approaches and future directions for social entrepreneurship research. Entrepreneurship Theory and Practice, 43(1), 82-115. https://doi.org/10.1177\%2F1042258717727718

Revista de Administração Contemporânea. (n.d.). Retrieved from https://rac.anpad.org.br/index.php/rac

Rosa, R. A., \& Romani-Dias, M. (2019). A presença e o impacto de periódicos brasileiros da área de administração, contabilidade e turismo em bases científicas. Revista Eletrônica de Ciência Administrativa, 18(3), 327-348. https://doi.org/10.21529/RECADM.2019014 
Rossoni, L. (2018a). Editorial: Em defesa das publicações em português. Revista Eletrônica de Ciência Administrativa, 17(3), I-XIII. https://doi.org/10.21529/ RECADM.2018ed3

Rossoni, L. (2018b). O Spell reduziu o efeito Mateus na citação de periódicos. Revista Eletrônica de Ciência Administrativa, 17(1): I-VIII. $\quad$ http://dx.doi.org/10.21529/ RECADM.2018ed 1

Scott, S. G., \& Lane, V. R. (2000). A stakeholder approach to organizational identity. Academy of Management Review, 25(1), 43-62. https://doi.org/10.5465/ amr.2000.2791602

Simsek, Z., Heavey, C., \& Jansen, J. J. (2013). Journal impact as a diffusion process: A conceptualization and the case of the Journal of Management Studies. Journal of Management Studies, 50(8), 1374-1407. https://doi. org/10.1111/joms.12007

Sinnayah, P., Rathner, J. A., Loton, D., Klein, R., \& Hartley, P. (2019). A combination of active learning strategies improves student academic outcomes in first-year paramedic bioscience. Advances in Physiology Education, 43(2), 233-240. https://doi.org/10.1152/advan.00199.2018

Sismondo, S. (2017). Post-truth? Social Studies of Science, 47(1), 3-6. https://doi.org/10.1177\%2F0306312717692076

Smith R. (2001). Measuring the social impact of research. BMJ (Clinical research ed.), 323(7312), 528. https://doi. org/10.1136/bmj.323.7312.528

Smith, D. R. (2012). Impact factors, scientometrics and the history of citation-based research. Scientometrics, 92(2), 419-427. https://doi.org/10.1007/s11192-0120685-x

\section{Autoria}

\section{Luciano Rossoni*}

Rua da Lapa, nº 86, Centro, 20021-180, Rio de Janeiro, RJ, Brasil.

E-mail: lrossoni@gmail.com

(C) https://orcid.org/0000-0003-2289-0879

\section{Rodrigo Assunção Rosa}

Rua Professor Pedro Viriato Parigot de Souza, $n^{\circ} 5300$, Cidade Industrial, 81280330, Curitiba, PR, Brasil.

E-mail: rodrigo.rosa@up.edu.br

(D) https://orcid.org/0000-0002-5559-2387

* Autor Correspondente

\section{Contribuições dos Autores}

1 autor: liderou a conceituação, curadoria de dados, análise formal, aquisição de financiamento, metodologia, recursos, software e supervisão. Contribuiu igualmente para a investigação, administração do projeto, validação, visualização, rascunho do artigo original e revisão e edição do artigo.

$2^{\mathbf{0}}$ autor: suporte à conceituação, curadoria de dados, análise formal, aquisição de financiamento, metodologia, recursos, software, supervisão e investigação. Contribuiu igualmente com a administração do projeto, validação, visualização, rascunho do artigo original e revisão e edição da redação.
Stinchcombe, A. L. (1965). Social structure and organizations. In J. G. March (Ed.), Handbook of Organizations (pp. 142193). Skokie, IL, USA: Rand McNally \& Company.

Sugimoto, C. R., Work, S., Larivière, V., \& Haustein, S. (2017). Scholarly use of social media and altmetrics: A review of the literature. Journal of the Association for Information Science and Technology, 68(9), 2037-2062. https://doi. org/10.1002/asi.23833

Tinoco, T. (2006). Padrões de citação na produção científica de administração no Brasil: 1997-2002. (Master's Thesis). Fundação Getulio Vargas, São Paulo, SP, Brasil.

Tolbert, P. S., \& Zucker, L. G. (1983). Institutional sources of change in the formal structure of organizations: The diffusion of civil service reform, 1880-1935. Administrative Science Quarterly, 28(1), 22-39. https:// doi.org/10.2307/2392383

Tonelli, M. J. (2019). Para comemorar: Novo fator de impacto da RAE. Revista de Administração de Empresas, 59(4), 224 224. http://dx.doi.org/10.1590/S0034-759020190401

Vanderstraeten, R. (2010). Scientific communication: Sociology journals and publication practices. Sociology, 44(3), 559-576. https://doi.org/10.1177/0038038510362477

Vessuri, H. (1995). Recent strategies for adding value to scientific journals in Latin America. Scientometrics, 34(1), 139 161. https://doi.org/10.1007/BF02019178

Wilson, J. R., Procheş, Ş., Braschler, B., Dixon, E. S., \& Richardson, D. M. (2007). The (bio)diversity of science reflects the interests of society. Frontiers in Ecology and the Environment, 5(8), 409-414. https://doi. org/10.1890/060077.1

\section{Financiamento}

Os autores agradecem à FAPERJ (Processo E-26/203.238/2017) pelo apoio financeiro.

\section{Conflito de Interesses}

Trata-se de um artigo convidado pelo Editor-chefe da RAC. A intenção é de contribuir para a consolidação da reputação e do legado da revista. Além disso, é um documento que registra, ao público interessado, a trajetória e a contribuição deste periódico. O primeiro autor participa da equipe editorial da RAC.

\section{Direitos Autorais}

A RAC detém os direitos autorais deste conteúdo.

\section{Verificação de Plágio}

A RAC mantém a prática de submeter todos os documentos aprovados para publicação à verificação de plágio, mediante o emprego de ferramentas específicas, e.g.: iThenticate.

\section{Método de Revisão por Pares}

Por tratar-se de Artigo Convidado, este conteúdo obteve a aprovação do editor-chefe e não foi submetido ao processo de revisão por pares duplo-cego (double-blind peer-review). 